\title{
Brain systems underlying the affective and social monitoring of actions: an
} integrative review

\author{
Leonie Koban ${ }^{1,2, *} \&$ Gilles Pourtois ${ }^{3}$ \\ ${ }^{1}$ Institute for Cognitive Sciences, University of Colorado Boulder \\ ${ }^{2}$ Swiss Center for Affective Sciences, University of Geneva \\ ${ }^{3}$ Department of Experimental Clinical and Health Psychology, Ghent University \\ * Corresponding author: \\ Leonie.Koban@colorado.edu \\ Institute of Cognitive Science \\ University of Colorado Boulder \\ Muenzinger D244 \\ 345 UCB \\ Boulder, CO 80309-0345 \\ Tel. +1 7202360707
}

\section{Gilles.Pourtois@ugent.be}

Department of Experimental Clinical and Health Psychology

Ghent University

Henri Dunantlaan 2

9000 Gent, Belgium

Tel. +3292649144 


\begin{abstract}
(max 170 words)
Action monitoring allows the swift detection of conflicts, errors, and the rapid evaluation of outcomes. These processes are crucial for learning, adaptive behavior, and for the regulation of cognitive control. Our review discusses neuroimaging and electrophysiological studies that have explored the contribution of emotional and social factors during action monitoring. Metaanalytic brain activation maps demonstrate reliable overlap of error monitoring, emotional, and social processes in the dorsal mediofrontal cortex (dMFC), lateral prefrontal areas, and anterior insula (AI). Cumulating evidence suggests that action monitoring is modulated by trait anxiety and negative affect, and that activity of the $\mathrm{dMFC}$ and the amygdala during action monitoring might contribute to the 'affective tagging' of actions along a valence dimension. The role of AI in action monitoring may be the integration of outcome information with self-agency and social context factors, thereby generating more complex situation-specific and conscious emotional feeling states. Our review suggests that action-monitoring processes operate at multiple levels in the human brain, and are shaped by dynamic interactions with affective and social processes.
\end{abstract}

Keywords: Anterior insula; dorsal cingulate cortex; mediofrontal cortex; amygdala; error monitoring; ERN; feedback processing; social cognition; emotions; cognitive control; emotioncognition interactions; meta-analysis 


\section{Overview and motivation}

In order to adapt their behavior, to detect and learn from errors, and ultimately to increase their chances of survival, humans and other animals have to monitor their actions (Rabbitt, 1966). Flexible regulation of behavior requires its constant evaluation in terms of performance and outcomes, as well as in terms of costs and future consequences. Action and error monitoring have been studied for several decades in psychology and neuroscience (for previous reviews see e.g. Bush et al., 2000a; Falkenstein et al., 2000; Taylor et al., 2007; Ullsperger et al., 2010), mainly using relatively abstract interference paradigms (such as Stroop, Flanker, Simon or go/no-go tasks), and primarily from a cognitive perspective. The first part of this review provides a brief overview of the classical findings in this literature, outlining the main methods (electrophysiology and brain imaging), as well as the central brain systems involved in performance and error monitoring. In the main part, we review and discuss a growing literature that suggests close ties of action monitoring systems with emotional and social processes. In line with other recent accounts that suggest reciprocal interactions between cognitive control and emotion processing brain systems in dorsal mediofrontal cortex (dMFC) (Etkin et al., 2011; Moser et al., 2013; Pessoa, 2008; Proudfit et al., 2013; Shackman et al., 2011; Shenhav et al., 2013), we propose that error and action monitoring is an intrinsically affective and social process. However, we show that meta-analytic activation maps support overlapping brain responses to error processing, emotional, and social information processing not only in dMFC, but also in several other brain regions, including anterior insula and lateral prefrontal cortex. Further, recent intracranial electrophysiological recordings showed error-related activity in the amygdala, suggesting this limbic region may contribute to affective responses to errors and negative action outcomes. In the closing part, we outline an integrative framework for 
understanding the brain systems underlying affective and social interactions with action monitoring, which may be crucial to foster behavioral control in real life.

\section{Behavioral and neurophysiological correlates of action monitoring}

\subsection{Basic concepts and behavioral findings}

Action monitoring has mainly been studied by investigating behavioral and neural correlates of conflict, response error, and feedback processing in various reaction time tasks (for recent comprehensive reviews, see e.g. Holroyd and Yeung, 2012; Shackman et al., 2011; Shenhav et al., 2013). In this context, conflict has been defined as crosstalk interference between different ongoing processes (Botvinick et al., 2001) and studied using interference or go/no-go tasks (for an overview on experimental paradigms see Nee et al., 2007; Shackman et al., 2011). Behaviorally, conflict is associated with longer reaction times and a greater number of errors than non-conflict trials (Botvinick et al., 1999; Gratton et al., 1992; Sheth et al., 2012).

Errors are incorrect responses (in relation to the task instructions) and occur more frequently in incongruent (conflict) than in congruent trials (Carter, 1998; Gehring and Fencsik, 2001; Gratton et al., 1992). They can be easily evoked as "false alarms" in no-go trials, especially when time pressure is high (e.g. Vocat et al., 2008) or when no-go trials are very infrequent (Simmonds et al., 2008). Errors are sometimes followed by post-error slowing, i.e. longer RTs on the (correct) trial following errors due to adjustments in response tendencies (Danielmeier et al., 2011; Danielmeier and Ullsperger, 2011; King et al., 2010) or as a reflection of attentional orienting to these deviant and worse than expected events (Notebaert et al., 2009; 
Wessel et al., 2012). Errors can lead to increased post-error accuracy (Danielmeier and Ullsperger, 2011), indicating a potential shift in speed/accuracy trade-off.

External feedback processing is studied with experimental tasks, in which participants are not able to infer the action outcome based on their response or based on an internal monitoring process exclusively (Gehring and Willoughby, 2002; Holroyd and Coles, 2002b; Miltner et al., 1997), but have to rely on externally provided feedback. Examples include gambling tasks in which outcome is randomized or probabilistic in nature (Eppinger et al., 2008; Frank et al., 2005), or time-estimation tasks (e.g. Hirsh and Inzlicht, 2008; Miltner et al., 1997). Feedback about the action outcome (e.g. win or loss, correct or incorrect) is usually presented as visual or auditory information (Walsh and Anderson, 2012).

\subsection{Investing the time-course of action monitoring with electrophysiology}

For several reasons, electrophysiology provides an important methodological approach to the study of action monitoring brain processes. First, techniques such as EEG and intracranial electrophysiological recordings allow inferences about the time course of neurophysiological processes underlying error and conflict processing (Pourtois et al., 2010) with millisecond temporal resolution that is unattainable by brain imaging methods based on more sluggish hemodynamic contrasts (such as fMRI or PET). Second, event-related potentials (ERPs) have revealed several phasic components of conflict, error, and outcome monitoring, which have specific temporal and topographical properties, such as the N2, error-related negativity (ERN), and feedback-related negativity (FRN). These ERP components may partially reflect a common underlying process (Van Veen and Carter, 2002; Wessel et al., 2012; Yeung et al., 2004) that is characterized by phasic bursts in theta band activity (Cavanagh et al., 2012; Cohen, 2011). Beyond this common functional role, they can be considered as characteristic physiological 
markers of conflict, error, and outcome processing (for overviews see Falkenstein et al., 2000; Simons, 2010). Given the combination of these properties, i.e. high time resolution and the specificity of action monitoring ERP components, electrophysiology can inform us about the temporal sequence of psychological processes during action monitoring, as well as the timing of their modulation by various affective, social, or cognitive factors.

Depending on the task characteristics, electrophysiological indices of action monitoring can be observed at different stages, during stimulus processing and motor preparation, response execution, or outcome evaluation (see Figure 1). When response conflict and errors can be detected before or during the onset of the motor response, monitoring is based on internal motor and task representations, as reflected in the stimulus-locked conflict N2 component, as well as the response-locked error-related negativity (ERN or $\mathrm{Ne}$ ) and error positivity $(\mathrm{Pe})$. On the other hand, performance monitoring has to rely on external feedback when there is no reliable internal information about the outcome at the time of action execution (Bediou et al., 2012; Heldmann et al., 2008; Holroyd and Coles, 2002b; Koban et al., 2012b), leading to the feedback-related negativity (FRN) that is locked to the presentation of visual feedback. The FRN is sometimes followed by a P300 to negative outcomes. These action monitoring ERP components (N2, ERN, Pe, and FRN) have been first described and studied for self-generated actions. Yet, an emerging literature suggests that similar components can be evoked for observed action outcomes, e.g. when watching the errors of another agent (see section 3.3 for an in-depth discussion). Figure 1 summarizes the different stages of action monitoring and the corresponding electrophysiological components, for self-generated and observed actions.

-- Please insert Figure 1 about here -- 


\subsection{Functional brain imaging results}

Functional brain imaging studies using fMRI and PET have shown that conflicts, as well as incorrect responses and negative performance feedback activate a widespread network of brain regions, comprising dACC/dMFC, anterior insula (AI) and frontal operculum, thalamus, and lateral prefrontal cortex (LPFC) (Carter et al., 1998; Kiehl et al., 2000; Menon et al., 2001; Shackman et al., 2011; Ullsperger et al., 2010). In contrast, positive performance feedback or monetary gains are associated with increased activity of the ventral striatum (de Bruijn et al., 2009; Delgado et al., 2000; Koban et al., 2013a; Thut et al., 1997).

A great amount of theoretical and empirical work has addressed the roles of medial and lateral prefrontal areas (for recent reviews on empirial and theoretical aspects, see Shackman et al., 2011; Shenhav et al., 2013) and their relationship to behavioral adjustments (King et al., 2010; Sheth et al., 2012). For example, an fMRI study by Kerns et al (2004; see also MacDonald et al., 2000) demonstrated that the dACC/dMFC responds to errors more than to correct responses, but also to correct conflict trials more than to incorrect conflict trials (but see Ullsperger and von Cramon, 2001). Importantly, these conflict-related signal changes in dMFC predicted both dIPFC activation and behavioral adjustments in subsequent trials (in terms of faster reaction times, Gratton et al., 1992), in line with theoretical accounts suggesting that conflict detection in dMFC triggers adaptive changes in cognitive control, which are implemented by LPFC (Botvinick et al., 2001; Cohen et al., 2004; Kerns et al., 2004).

Together with ERP results, brain imaging studies thus confirm the involvement of dACC/dMFC in conflict and action monitoring (Ridderinkhof et al., 2004). However, it remains an open question whether errors, conflicts, and outcomes elicit common activations on a smaller 
spatial scale and whether they are related to differential connectivity patterns with other brain regions. For instance, recent research has demonstrated dissociable brain activations for these different events, with errors activating more anterior and ventral subregions, and conflicts more dorsal parts of the dMFC (e.g. Desmet et al., 2011; Garavan et al., 2003; Nee et al., 2011; Ullsperger and von Cramon, 2001).

Whereas the roles of dMFC and LPFC in action monitoring and regulatory processes have been intensively researched and debated (for reviews and theoretical frameworks see Alexander and Brown, 2011; Botvinick, 2007; Rushworth et al., 2007; Shackman et al., 2011; Shenhav et al., 2013), the functions of other regions commonly activated by conflicts and errors are less clear. The anterior insula (AI), together with frontal operculum and inferior frontal gyrus (IFG), is one of the most consistently activated regions in response to errors, negative feedback, and conflict (for a recent review, see Chang et al., 2013; Koban et al., 2013a; Koban et al., 2013b; Nee et al., 2007; Ullsperger et al., 2010), but its role remains unspecified in most models of action and conflict monitoring (for exceptions see Brass and Haggard 2010; Ullsperger et al., 2010). Using an anti-saccade task, Klein et al. (2007) showed that the left AI is more activated for aware than unaware errors. This led to the hypothesis that AI is important for the conscious detection of errors (Klein et al., 2007; Ullsperger et al., 2010), in line with studies highlighting the role of this region in interoception and bodily awareness (Craig, 2009; Critchley et al., 2004). Given the involvement of AI in emotions and the representation of bodily states of self and others (Craig, 2009; Kober et al., 2008; Lamm et al., 2011; Singer et al., 2009), it may be implicated in the affective component of error and outcome processing (Brass and Haggard, 2010), as outlined in the next sections. 


\section{Emotional and social effects on action monitoring}

In the next sections, we provide evidence for important affective and social influences on action and performance monitoring. Using term-based meta-analytic images, we first explore anatomical convergence between brain areas involved in action monitoring as well as in affective and social processes, and briefly discuss their role in those different domains. Then, we present recent empirical findings that suggest a close relationship between performance monitoring and affective processes. We argue that actions are automatically appraised along an affective valence dimension in the ACC and amygdala concurrently, whereas the AI may integrate action outcomes with agency and social context, thereby potentially eliciting more complex and situation-specific emotions such as shame or guilt.

\section{1 Anatomical convergence between error monitoring, emotional, and social} processing

Several of the regions involved in action monitoring have also been associated with affective and social processes (for previous meta-analysis for social and affective processes see Bzdok et al., 2013; Kober et al., 2008; Lamm et al., 2011; Lindquist et al., 2012; Overwalle, 2009; Wagner et al., 2012a). To characterize the overlap between brain regions consistently activated for error monitoring as well as for emotion and social cognition tasks, we employed term-based meta-analytic images of the NeuroSynth database (Yarkoni et al., 2011a; Yarkoni et al., 2011b). NeuroSynth is an ambitious project aimed at automatic identification, extraction, and synthesis of human functional brain imaging results and corresponding meta-data (Yarkoni et al., 2011a). It uses text-mining techniques to detect frequently used terms (as proxies for concepts of interest) in the neuroimaging literature: terms that occur at a high frequency in a given study are then associated with activation coordinates in this publication, allowing for automated generation 
of meta-analytic activation maps based on a very large number of studies (currently 5809 published papers, as of August 2013). Despite the automaticity and the potential noise resulting from the association between term frequency and coordinate tables, this approach has been shown to be very robust and reliable for broad constructs (Yarkoni et al., 2011a).

Using the NeuroSynth web interface (www.neurosynth.org), we extracted forward inference brain images for the terms 'Errors', 'Emotion', and 'Social' (downloaded on July 18, 2013, see supplementary materials for a listing of included studies). These images were overlaid on a standard anatomical template and shown at a FDR-corrected threshold of $p<0.05$ (see Figure 2A for 'Errors' and 'Emotion', Figure 2B for 'Errors' and 'Social'). In line with the literature reviewed above, 'Error'-related activity was found in dMFC (including cingulate and medial frontal gyri), LPFC (middle and inferior frontal gyri), AI, nucleus caudatus, and parietal cortex (inferior and superior parietal lobule). 'Emotion' activated bilateral amygdala, AI, dMFC (medial and superior frontal gyri), inferior frontal gyrus, fusiform gyrus, and inferior temporal gyrus. Widespread brain activations were further found for 'Social', including medial prefrontal cortex (subgenual cingulate, medial frontal gyrus), dMFC, LPFC (inferior frontal and middle frontal gyri), AI, amygdala, thalamus, inferior and superior parietal lobule, precuneus, fusiform and inferior occipital gyri, as well as middle and superior temporal gyri.

For the conjunction analysis, we used a conservative minimum statistics approach (Nichols et al., 2005). Very similar results were found for the conjunction ['Errors' AND 'Emotion'], as well as for ['Errors' AND 'Social'] (see clusters depicted in yellow, Figure 2), indicating overlapping activations in $\mathrm{dMFC}$, AI, LPFC, and basal ganglia for all of these three domains. These brain areas may therefore be involved in the integrative processing of action monitoring with affective and social factors. 


\section{-- please insert Figure 2 about here --}

Anterior cingulate cortex has been traditionally viewed as an important hub for emotional processing (Papez, 1937; Tow and Whitty, 1953), and considerable debate has evolved around the question of how emotional and cognitive information processing are organized and integrated in cingulate cortex (Drevets and Raichle, 1998). Earlier accounts have proposed separate emotional and cognitive subdivisions of ACC (Bush et al., 2000b; Devinsky et al., 1995), with the more anterior part being assigned a role in affective processing and the dorsal section in cognitive processing. However, this view has been challenged by accumulating evidence indicating that dorsal ACC, or more broadly dorsal mediofrontal cortex (dMFC), is involved in both cognitive and emotional processing (see meta-analyses by Etkin et al., 2011; Shackman et al., 2011), and could therefore constitute an important hub for emotion-cognition interactions (Pessoa, 2008). The functional model by Etkin et al puts forward that the dMFC is involved in affective appraisal and the expression of emotions, whereas more ventral parts of ACC and medial prefrontal cortex are important for their regulation. Similarly, Shackman et al. (2011) posit a central role of dMFC in negative emotion, pain, and cognitive control processes. The "adaptive control hypothesis" (Shackman et al., 2011) suggests that the anterior midcingulate cortex / dMFC is engaged when there is uncertainty about actions and their potentially aversive outcomes, and that this mediofrontal region integrates events such as errors, pain, or conflict, which require adjustments in adaptive control (see also Botvinick et al., 2001; Seeley et al., 2007).

However, our meta-analytic conjunction analysis indicates that dMFC might not be the only candidate for cognitive-affective integration during action monitoring (see also Pessoa, 
2008). Other regions, especially AI and lateral prefrontal cortex are activated by emotional, social, and error monitoring processes as well, and might therefore also constitute important hubs between different systems (Pessoa, 2008; Sridharan et al., 2008) and for convergence between action monitoring and socio-affective information (Brass and Haggard, 2010; Koban et al., 2013a; Ullsperger et al., 2010). In the following sections, we describe behavioral and neurophysiological evidence for affective and social influences on action monitoring, and interactions of these processes in $\mathrm{dMFC}$ and $\mathrm{AI}$.

\subsection{Interactions between affective processes and error monitoring}

Conflicts or response errors have often been seen in the literature as distinctive or special events (in the sense of being unexpected, surprising and deviant, sometimes even considered to be "noisy"). They inform therefore about the regulation of behavioral control - i.e. how specific brain processes are engaged following these adverse outcomes in order to enhance cognitive control (through putative top-down attention control mechanisms), and eventually restore the normal mode of processing, or homeostasis (Weissman et al., 2006; Wessel et al., 2012).

Although these processes have mainly been studied from a cognitive framework, growing evidence suggests that they are not immune to emotions, but interact with motivational and affective factors. Psychophysiological and behavioral studies showed that response errors (and conflicts) activate a defensive motivational system (recently reviewed by Dreisbach and Fischer, 2012; Proudfit et al., 2013). For example, response errors during a flanker task yield larger skin conductance responses and greater heart rate deceleration than correct decisions (Hajcak et al., 2003b), as well as a larger potentiation of the startle reflex (Foti and Hajcak, 2009). These findings suggest that response errors may be perceived as aversive and distressing events (Spunt 
et al., 2012), which are associated with enhanced arousal and increased activation of the autonomic nervous system (Hajcak et al., 2003b).

\subsubsection{Involvement of the amygdala in action monitoring}

Direct hints regarding the involvement of emotion-related brain areas were obtained recently by means of intracranial recordings in humans (Pourtois et al., 2010). In this neurophysiological study, two pharmacoresistant patients, implanted invasively with intracranial depth electrodes in the dorsal ACC and amygdala prior to surgery for refractory epilepsy, performed a go/no-go task (Aarts and Pourtois, 2010; Koban et al., 2010; Vocat et al., 2008). Results showed that response errors in this task were associated with a distinctive increase of phasic theta bursts in the dorsal ACC rapidly following the onset of these adverse events, consistent with scalp ERP results and the generation of the ERN component (see Cavanagh et al., 2012). Further, intracranial local field potentials (iLFPs) recorded in the amygdala revealed that this mesio-temporal lobe structure showed increased electrophysiological activity following errors compared to correct actions (Pourtois et al., 2010). Moreover, a selective coupling in the theta band between dorsal ACC iLFPs and amygdala iLFPs suggested a dynamic cross-talk between these two brain regions during error detection, and action monitoring more broadly. The involvement of the amygdala in action and error monitoring has been confirmed by functional brain imaging (Pourtois et al., 2010), including in healthy adult participants (Polli et al., 2008; Polli et al., 2009; Sagaspe et al., 2011).

Although compelling, the evidence for autonomic responses and for the involvement of the amygdala (or other emotion control brain systems besides or beyond the dorsal ACC) in action monitoring and error detection remains largely correlational in nature, and not all imaging studies have reported amygdala activation to response errors or negative feedback (see meta- 
analysis, Figure 2). Recent neurophysiological evidence suggests however that the amygdala, and more specifically the basolateral nucleus, may play an important role in error but not conflict monitoring (Kashtelyan et al., 2012). These findings suggest that the amygdala might be implicated in error monitoring mostly when errors imply learning. More generally, they are compatible with earlier neurophysiological findings showing that the amygdala, together with other sub cortical structures, might be involved in "prediction error" or "surprise", i.e. detection of discrepancy between expected and obtained outcome (see Holland and Gallagher, 2006).

\subsubsection{Evidence from affective priming studies}

Enhanced amygdala and autonomic nervous system activity accompanying response errors does not inform about whether valence-specific effects can be obtained as a function of the perceived goal conduciveness (Scherer, 1984, 1988) of simple self-generated actions. In this alternative framework, specific appraisal monitoring processes are assumed to be involved in the processing of the valence (opposed to arousal value) of simple actions, such as to mark incorrect actions as bad/negative and correct ones as good/positive (Aarts et al., 2012). In essence, this online evaluative process would promote adaptive behavior not only by increasing arousal and defense systems in response to errors, but by "tagging" motivational or affective meaning to each and every action.

Recently, some advancement has been made at the methodological level in order to corroborate the assumption that the monitoring of simple actions made during standard interference tasks is not devoid of emotion. Aarts and colleagues (2012) sought to test whether actions made during a simple go/no-go task might be processed rapidly along a genuine affective valence dimension. Their hypothesis was that incorrect actions (errors) should be associated with negative affective valence ("bad"), while conversely correct actions should be tagged as positive 
("good"). For this purpose, Aarts et al. made use of the evaluative priming paradigm (Fazio et al., 1986), in which each action made during the primary go/no-go task served as a prime for a secondary word discrimination task, unbeknown to the participants. This secondary task required participants to discriminate the valence (positive versus negative) of an emotional word that was presented for a few milliseconds on the screen directly following every response made in the primary task. Aarts et al. reasoned that if specific emotion systems are engaged rapidly during action monitoring, then a significant priming effect between the action (prime) and the written word (target) might arise. More specifically, they conjectured that errors made during the primary task would automatically prime negative affect and therefore speed up the detection of subsequent negative compared to positive words. Conversely, correct responses in the primary task may prime positive affect and lead to faster discrimination of positive than negative words. The results of this study confirmed their predictions (Aarts et al., 2012). As such, these findings go beyond earlier results that showed that response errors enhance autonomic arousal and activate a defensive motivational system (Hajcak and Foti, 2008). Additionally, they demonstrate that simple actions are constantly monitored in terms of their valence. This means not only marking response errors as bad, but also identifying correct actions as good events. This dynamic process, directly linking actions and outcomes to positive and negative affective states (see also Brass and Haggard, 2010; Craig, 2009; Ullsperger et al., 2010) appears especially important to promote learning and to enable adaptive behavior in an ever-changing and complex environment.

Interestingly, these priming results were observed when the time interval between the action and the word was set to 300 or $600 \mathrm{~ms}$, but not for intervals of $1000 \mathrm{~ms}$, suggesting that the association of actions with affective valence is rapid and automatic. This timing is in line with the early amygdala responses to errors and correct actions evidenced in intracranial 
recordings, as reviewed here above (Pourtois et al., 2010). Given the important role of the amygdala in the detection of emotionally salient external stimuli (Anderson and Phelps, 2000; LaBar et al., 1998; Phelps, 2006; Sander et al., 2003; Vuilleumier, 2005; Whalen et al., 2001), this structure could be similarly involved in the rapid affective monitoring of internally generated action events (Barbas et al., 2011). Similar behavioral priming effects have been observed for incongruent compared to congruent trials in the flanker task (Dreisbach and Fischer, 2012), suggesting that not only errors, but also conflict and the need for increased cognitive control are automatically perceived as aversive and associated with negative valence (Botvinick, 2007; Dreisbach and Fischer, 2012). Interestingly, behavioral results also suggest that although conflicts and interference may be perceived as aversive, they can acquire positive valence, if participants are able to resolve conflict, i.e. to overcome task interference (Schouppe et al., in revision). Hence, conflicts may be perceived as negative or as positive depending on their processing stage and on the potential for resolution (i.e., coping potential), suggesting that interaction effects between action monitoring and affective processes are flexible and dynamic (Gentsch et al., 2013).

Aarts and colleagues (2013) extended their earlier findings by using ERPs to investigate the electrophysiological time-course of this affective priming by simple actions. They found that the amplitude difference between the ERN for errors minus the CRN for correct responses in the go/no-go task was correlated with the magnitude of the evaluative priming effect in the secondary word discrimination task. This suggests that the ERN-CRN amplitude difference might actually reflect the differential affective values of incorrect versus correct actions, in line with evidence that the ERN is correlated to the significance of errors (see also Luu et al., 2000; Olvet and Hajcak, 2008; Simons, 2010). Another distinctive property of these priming effects 
was that high levels of negative affect and trait anxiety/apprehension were associated with weaker affective priming effects elicited by errors versus correct responses (Aarts et al., 2012). This indicates that personality traits and individual differences in negative affect and internalizing disorders may modulate key processes during action monitoring, as it will be discussed in the next section.

\subsubsection{Evidence from individual differences and psychopathology}

One of the most robust findings in the error monitoring literature is an enhanced ERN/Ne component in participants with high trait negative affect (see Moser et al., 2013; Olvet and Hajcak, 2008; Simons, 2010; Vaidyanathan et al., 2012). Using standard interference tasks, several ERP studies have reported greater ERN/Ne (and often CRN) components in patients with anxiety or internalizing disorders (Krueger et al., 2001), including obsessive compulsive disorders (Carrasco et al., 2006; Endrass et al., 2008; Endrass et al., 2010; Gehring et al., 2000; Hajcak and Simons, 2002; Johannes et al., 2001; Stern et al., 2010), depression (Aarts et al., in press), and generalized anxiety disorders (Weinberg et al., 2010). Likewise, even healthy participants with higher levels of subclinical trait anxiety were shown to have increased ERN and CRN components (Aarts and Pourtois, 2010; Hajcak et al., 2003a; Moser et al., 2013). Further, the amplitude of these components has been related to sensitivity to punishment, a trait that strongly correlates with anxiety, harm avoidance, neuroticism, and negative affect (Boksem et al., 2006).

Interestingly, in all these previous action-monitoring studies, the effects of negative affect were selective for the ERN component, while leaving the subsequent Pe component unaffected. The component-specific modulation of action monitoring by negative affect is compatible with evidence that the ERN and Pe components are likely generated by different brain systems and 
functionally dissociable (Dhar et al., 2011; Koban et al., 2012a; Overbeek et al., 2005b; Ridderinkhof et al., 2009; Wessel, 2012). This suggests that modulatory effects exerted by dispositional negative affect and anxiety disorders may selectively enhance very early action monitoring and error detection brain processes, whereas later-potentially regulatory—processes may be preserved (but see Aarts et al., in press, for an amplitude modulation of the $\mathrm{Pe}$ component in major depression).

Based on this evidence, some authors have put forward the proposal that the ERN could be considered as a reliable endophenotype or biomarker for internalizing disorders (Olvet and Hajcak, 2008; Proudfit et al., 2013). Yet, it remains currently unclear why internalizing disorders would be associated with overactive early error monitoring processes at the level of the ERNCRN component exclusively. Interestingly, the observation of an overactive ERN is not paralleled by any behavioral deficits or other changes in task performance in patients compared to controls. In other words, high-anxious individuals usually respond as fast and as accurately as low-anxious individuals, yet their electrophysiological response to errors is increased compared to low-anxious participants (see meta-analysis by Moser et al., 2013). Further, this enhanced electrophysiological response is not only observed for the ERN, but in some studies also for the CRN, i.e. in the electrophysiological response to correct responses (Aarts and Pourtois, 2010). Although this CRN effect is not found consistently across all studies and therefore might be specific for speeded go/no-go paradigms, this point casts doubts on the interpretation that negative affect influences the processing of response errors selectively. Instead, a more parsimonious account posits that high anxiety (apprehension, as opposed to anxious arousal) and more generally internalizing disorders may be associated with increased dMFC responses to both incorrect and correct but risky actions. 
While mounting evidence suggests altered action monitoring at the level of the response, the literature exploring potential effects of anxiety and negative affect on the monitoring of external performance feedback and the FRN is rather scarce. One study (De Pascalis et al., 2010) found that individuals who were more sensitive to punishment (as evidenced using the BIS-BAS scale, see Carver and White, 1994) had a larger FRN to monetary losses in a go/no-go task. By contrast, two other ERP studies reported reduced FRN amplitudes for high, compared to low anxious individuals (Gu et al., 2010; Simons, 2010). Similarly, Aarts \& Pourtois (2012) found that sub-clinical high trait anxiety was associated with blunted FRN components to evaluative feedback. By contrast, depression does not seem to reduce the FRN component (Mies et al., 2011). Together, these findings suggest that modulatory effects of negative affect on action monitoring may not be restricted to internally driven (i.e., response-related) monitoring processes, but extend to externally driven (i.e., feedback related) processes, but with potentially opposite effects. To the best of our knowledge, no ERP study to date has reported an enhanced FRN component in anxiety or negative affect. This observation challenges the assumption that this ERP component reflects the counterpart of the ERN when action monitoring is primarily achieved based on external evaluative feedback (as opposed to internal motor or cognitive effects for the ERN, see Gehring and Willoughby, 2002; Heldmann et al., 2008; Holroyd and Coles, 2002a; Miltner et al., 1997) and that both components can be related to a common theta band oscillatory process (Cavanagh et al., 2012; Cohen, 2011).

\subsection{Social effects on action monitoring}

Beyond the evidence of emotion effects on action monitoring, a rapidly growing literature suggests important social influences on error and outcome processing. In general, these 
studies can be organized into two main questions: The first is how people monitor others' actions and learn from observation. The second main research question is how social context modulates the monitoring of our own actions. The answers to these questions will inform us on the brain mechanisms underlying action monitoring in interpersonal and group settings, as well as how human behavior may be adjusted to the requirements of social life in more general ways.

\subsubsection{Monitoring and evaluating the actions of others}

In line with the general idea of motor simulation and mirror neuron systems (Gallese et al., 2004; Keysers and Gazzola, 2006), monitoring of others' errors and action outcomes might be based on similar mechanisms than the processing of self-generated actions, and involve the motor cortex and interconnected cingulate areas (Fadiga et al., 2005; van Schie et al., 2004). When watching a confederate or another participant performing an interference or go/no-go task, observation of their response errors leads to a specific ERP component, the observer ERN (oERN, see also Figure 1). The oERN resembles the ERN in its frontocentral topography and sources in the dMFC (Miltner et al., 2004; van Schie et al., 2004). Interestingly, the timing of the oERN seems to depend on the type of experimental task, as well as on the social relationship between observer and agent. Whereas the oERN in flanker tasks peaks around 250-300ms after observed motor errors (de Bruijn and von Rhein, 2012; Miltner et al., 2004; van Schie et al., 2004), it has been found much earlier ( 30ms and $\sim 140 \mathrm{~ms})$ in go/no-go task (Bates et al., 2005), but only when the relationship between participants was cooperative, as opposed to competitive (Koban et al., 2010). This has led to the suggestion that cooperation might enable the monitoring of observed actions based on shared simulated motor and task/goal representations (Sebanz et al., 2006a; Sebanz et al., 2006b), whereas participants may rely on purely visual and conceptual information during competition (Koban et al., 2010). In flanker tasks, vicarious errors might be 
harder to monitor, as they require detecting a mismatch between required response and actual response (e.g. left versus right key press), compared to go/no-go tasks where they could be detected much more easily (any response in a no-go trial is an error). Our observation that the amplitude of the early oERN was highly correlated with an observer N2 component (Koban et al., unpublished data) corroborates this interpretation.

The oERN is followed by a frontocentral positivity, the observer Pe (oPe, Carp et al., 2009) around 300-600ms after another person's error. Likewise, when visual performance feedback is presented following others' actions or gambling decisions, an observer FRN (oFRN) effect can be seen, with a very similar latency (around 200-350ms) and topographical pattern (although slightly smaller in amplitude) to the player FRN (Fukushima and Hiraki, 2009; Leng and Zhou, 2010; Yu and Zhou, 2006). Given their topographical and temporal similarities, the oERN, which is locked to another person's motor response, and the feedback-locked oFRN might potentially reflect the same or a very similar monitoring process.

In line with these electrophysiological results, fMRI studies have shown increased BOLD activity in dMFC for observed errors compared to observed correct trials (de Bruijn et al., 2009; Newman-Norlund et al., 2009; Shane et al., 2008), as well as in other regions such as AI, IFG, together with parietal and occipital areas (Koban et al., 2013a; Shane et al., 2008), indicating that activations for vicarious and self-generated errors may only partially overlap (Koban et al., 2013a; Shane et al., 2008).

The findings of parallel brain responses to self-generated and observed action errors have recently been confirmed using single-cell recordings in macaque mediofrontal cortex (Yoshida et al., 2012). This study showed enhanced firing in a large number of MFC neurons during observed errors compared to observed correct actions of another monkey, as well as during 
reward delivery to the other monkey (Yoshida et al., 2012). Interestingly however, most of these neurons did not respond to self-generated errors, indicating parallel but separate neural populations for the monitoring of self- and other-generated actions (Yoshida et al., 2012).

Error and feedback observation is modulated by several relationship factors between observer and agent. de Bruijn et al. (2009) investigated brain responses to observed performance feedback in cooperation vs. competition (see also Koban et al., 2012). These authors demonstrated activation of dMFC for errors compared to hits independent of context, whereas the ventral striatum responded as a function of the subjective reward value of errors vs. hits (higher striatum activation for hits in cooperation, and for errors in competition). Similarly, it has been shown that other persons' positive outcomes activate the ventral striatum more when they are perceived as more similar to the self (Mobbs et al., 2009), in line with the assumption that affective responses to observed outcomes depend on the relationship between self and other (see also Carp et al., 2009; Itagaki, 2008; Kang and Hirsh, 2010; Koban et al., 2010; Marco-Pallares et al., 2010). Additionally, individual differences in personality may influence the processing of observed actions and errors, especially perspective taking and empathy (Koban et al., 2012b; Rak et al., 2013; Thoma and Bellebaum, 2012). This is consistent with evidence from studies on error monitoring in conditions such as psychopathy or antisocial personality disorder, which are characterized by abnormally low empathy. Individuals with psychopathy have been demonstrated to show normal ERP responses to self-generated, but reduced ERP amplitudes to observed errors and correct responses (Brazil et al., 2011). Thus, as much as one's own, selfgenerated actions are evaluated on an affective dimension, being able to understand the emotions of others might be an important prerequisite for monitoring and understanding observed actions. 


\subsubsection{Social influences on the monitoring of self-generated actions}

Evidence of interaction effects between the monitoring of self- with other-generated actions comes from behavioral studies investigating post-error adaptation effects in social context. Several experiments have shown that post-error slowing does not only occur following one's own errors, but also when observing another person inadvertently committing an incorrect response (de Bruijn et al., 2011; Núñez Castellar et al., 2011; Schuch and Tipper, 2007). Interestingly, this effect has been found to be greater in cooperative compared to competitive interpersonal settings (de Bruijn et al., 2011; Núñez Castellar et al., 2011), which could be explained either by larger shared (motor) representation in the cooperative context, or alternatively by differential affective valence of observed errors in the two settings (Núñez Castellar et al., 2011).

Surprisingly, only recently ERP or fMRI studies have been conducted to investigate how brain responses to one's own action outcomes are modulated by social factors. For instance, a recent study (Van Meel and Van Heijningen, 2010) found an FRN for negative as compared to positive feedback during a learning task only when participants performed the task in a competitive setting, but not in an individual control condition. This result could indicate that the mere presence of other persons may enhance the processing of feedback, potentially as an effect of social comparison (Boksem et al., 2011a). Further, the emotional appraisal of others may affect performance monitoring: for instance, when presenting facial expressions of disgust as task cues, one study found increased ERN amplitudes compared to other facial expressions (Boksem et al., 2011b).

Indeed, actions in real life can have important consequences for other people, and it is thus not surprising that the social relationship between agent and observer, as well as other 
context factors can have profound influences on their monitoring and appraisal. FMRI results indicate that the dorsomedial prefrontal cortex shows higher activation during error monitoring in social relative to individual settings (Radke et al., 2011). In a recent ERP study, Koban et al. (2012) showed that the FRN was increased in cooperative compared to competitive context, with underlying sources in the dorsomedial PFC, LPFC, and temporoparietal junction (TPJ), all these regions being typically involved in social cognition (see Figure 2, and cf. Kelley et al., 2002; Mitchell et al., 2005; Saxe and Wexler, 2005). This increase in FRN amplitude was followed by a feedback-P300 effect that was specific for self-generated action outcomes in cooperative context. Moreover, the P300 was generated by sources in dMFC and AI and correlated with individual differences in trait empathy. Given the increased social relevance of negative performance when playing as a team, this effect could therefore reflect an increased affective response to negative feedback in cooperative context (Koban et al., 2012b).

To test more directly how humans integrate information about the potentially detrimental consequences of their actions for others, Koban et al. (2013) recently developed a new fMRI task, in which half of the error trials would lead to painful heat stimulation to a friend outside the scanner. Behaviorally, errors that caused pain to the friend were associated with increased feelings of guilt, shame, and higher ratings of empathic pain. These effects were paralleled by increased activations in dMFC, AI and dIPFC. Importantly, left AI and dlPFC showed interactions between action agency and empathic pain, indicating that these regions may integrate the processing of self-generated errors with the social consequences of actions (Koban et al., 2013a). This integration process should be crucial for the generation of moral emotions such as guilt and shame that are associated with self-generated actions that have socially negative 
consequences (Chang et al., 2011; Koban et al., 2013a; Wagner et al., 2012b; Wagner et al., 2011; Yu et al., 2013).

How outcomes of our decisions are evaluated also depends on what results alternative counterfactual actions would have had. For instance, if we pick one of two alternative bets and we lose, we may experience the feeling of regret, especially when we see that the other option would have been a winning one (Coricelli et al., 2005). The impact of such counterfactual choices is even more pronounced in social settings, indicating that these may provide additional information for learning (Coricelli and Rustichini, 2010). One ERP study indicates that the FRN to one's own outcomes might be modulated as a function of whether a co-player wins or loses at the same time (Qiu et al., 2010). In an fMRI study on social comparison, dACC activation was related to envying others' success, whereas schadenfreude was associated with ventral striatum activity when gloating over the misfortune of a previously envied person (Takahashi et al., 2009). Other investigations (Bault et al., 2008; Bault et al., 2011) used a lottery choice task that enabled the comparison of actual outcome to the (counterfactual) outcome of the non-chosen lottery. In half of the trials, the participants could additionally observe the outcome of choices made by another player. These authors found greater emotional responses to outcomes and counterfactual choices in the social different-outcomes condition, i.e. when the gains did not only lead to relief, but to gloating, and losses were not only associated with regret, but with envy (Bault et al., 2008; Bault et al., 2011). These behavioral findings were paralleled by higher BOLD activation of medial prefrontal cortex, striatum, TPJ, and DLPFC for gains in social context that were paired with losses for the other player, indicating a highly competitive component of outcome evaluation (Bault et al., 2011). 
Together with other previous behavioral and brain imaging studies, these results highlight the importance of social factors in action outcome evaluation and for behavioral adjustments, as well as the interplay between brain regions involved in social cognition on the one hand and reward and error processing mechanisms on the other hand. Further, studying the effects of social context on action monitoring may not only help understanding the interplay of the different functional networks in adaptive behavioral control, but also allow eliciting and studying complex emotions such as regret, envy, guilt, pride, and gloating in experimentally wellcontrolled settings (Chang and Koban, 2013). Ultimately, it may also contribute to a better understanding of psychiatric conditions such as psychopathy, autism, or alexithymia, which may be shaped by impaired processing of social-affective aspects of action monitoring in different prefrontal and limbic regions.

\section{Towards an integrative framework of action monitoring}

Taken together, our review of the literature suggests that action monitoring is strongly influenced by a number of affective and social factors. This is in line with the idea that adaptive control of behavior in real life requires the constant integration of various processing streams and sources of information.

Demonstrating integration of several processes requires showing that a given region responds to all of those processes, and that this region shows interaction effects between them (Gray et al., 2002; Gu et al., 2012). Using term-based meta-analytic images, we found evidence for the first premise and demonstrated extensive overlap between action monitoring, emotion processes, and social cognition in $\mathrm{dACC} / \mathrm{dMFC}$ and bilateral AI, plus lateral prefrontal areas. Previous anatomical and connectivity studies have shown that dMFC and AI are highly 
interconnected and constitute a cingulo-opercular functional network (Modha and Singh, 2010), which has been suggested to play an important role in the detection of salient events and the need for changes in cognitive control (Nee et al., 2007; Seeley et al., 2007; Sridharan et al., 2008). In parallel, hyperactivity of the cingulo-opercular network has been linked to anxiety and anxiety disorders (Etkin, 2010; Etkin and Wager, 2007; Kim et al., 2011; Sylvester et al., 2012).

In line with the idea of integrative processing of affective factors and action monitoring, EEG studies have revealed important influences of negative affect and anxiety on early action monitoring components. Most of these empirical results suggest highly correlated activity in the dMFC and AI during action monitoring, as well as during other tasks and processes (Craig, 2009; Ullsperger et al., 2010). Yet, most theoretical accounts have focused on either one of these two regions (and ignored the other) or treated both as an entity (e.g. as a cingulo-opercular network). Few attempts have been made to dissociate and contrast the contributions of dMFC and $\mathrm{AI}$ in error and action monitoring specifically, and in other domains more generally (but see Craig, 2009; Critchley et al., 2004; Ullsperger et al., 2010). In what follows, we propose that effects of emotional and social factors may be slightly different in these two regions and potentially reflect dissociable processes. The main assumption of this framework is that, within this cingulo-opercular functional network, emotional and social influences on action monitoring likely operate at different levels and latencies, and through different neuroanatomical routes.

\subsection{Automatic affective tagging of actions}

The results compiled in this review bolster the assumption that emotional and social influences on action monitoring may arise as a consequence of integrative processing of affect and action outcomes in dMFC and AI (see also Pessoa, 2008; Shackman et al., 2011), as outlined 
in Figure 3. It has been demonstrated that error and conflict detection are accompanied by phasic responses in the limbic structures such as the amygdala (Kashtelyan et al., 2012; Pourtois et al., 2010). Hypothetically, this structure responds to the specific affective or motivational value of action outcomes (Aarts et al., 2012). According to this framework, each simple action is not only deemed correct (goal conducive) or incorrect (goal obstructive) by means of phasic dACC activity rapidly following its onset, but also likely tagged 'automatically' as good or bad rapidly following the onset of the action. This 'affective tagging' might explain the enhanced synchrony (in the theta band, selectively) seen between dACC and amygdala during action monitoring and error detection (Pourtois et al., 2010). Given the role of the amygdala in vigilance (Davis and Whalen, 2001) and in the detection of relevant events (Sander et al., 2003), one possibility accounting for these neurophysiological effects during action monitoring is that this mesiotemporal lobe structure directly receives information from the dACC to process the motivational significance of actions, and eventually mediates the differential autonomic arousal to response errors, as opposed to correct responses (Hajcak et al., 2003b; Proudfit et al., 2013). Ultimately, this evaluative process could foster adaptive behavior by helping the organism to quickly identify salient or threatening actions that are associated to positive vs. negative affective states. Presumably, these affective processes during action monitoring are captured by systematic amplitude variations at the level of the ERN (Aarts et al., 2013; Compton et al., 2013; Luu et al., 2000; Moser et al., 2013; Proudfit et al., 2013).

\subsection{Perception of social agency during action monitoring}

Our review further suggests that observed errors and action outcomes evoke similar electrophysiological components and partially overlapping brain activation than self-generated 
errors and actions (de Bruijn et al., 2009; Koban et al., 2013a; Koban et al., 2012b; Miltner et al., 2004; Shane et al., 2008; van Schie et al., 2004), although they might be based on separate neuron populations (Yoshida et al., 2012). Monitoring others' actions may enable us to interact efficiently during joint action (Sebanz et al., 2006a; Vesper et al., 2010) and to learn by observation (Bellebaum et al., 2010; van Schie et al., 2004). Yet, an unresolved question concerns the processes that allow the attribution of error agency. An integrative framework of action monitoring has to incorporate a mechanism that indicates whether it is the 'self' or another agent that is responsible for a specific action outcome (Brass et al., 2009; Gallagher, 2000; Georgieff and Jeannerod, 1998).

A plausible solution is that the brain compares action predictions (i.e. a motor reference copy) with the actual sensorimotor consequences of these actions (Blakemore et al., 1998; Chambon et al., 2012; Farrer and Frith, 2002; Sato and Yasuda, 2005). Discrepancy between predicted and actual motor behavior is associated with activation of the angular gyrus in the parietal lobe (Chambon et al., 2012; Farrer et al., 2008; Farrer and Frith, 2002; Miele et al., 2011), which could thereby reversely encode the amount of perceived self-agency (Chambon et al., 2012). This is consistent with a role of this inferior parietal region in the attribution of motor control to other agents (Ruby and Decety, 2001).

Conversely, when investigating positive brain correlates of self- versus other-agency, Farrer \& Frith (2002) reported activation in the left AI in addition to motor control-related regions such as supplementary motor area, sensorimotor cortex, and cerebellum (see also David et al., 2006). Similarly, Brass \& Haggard (2010) recently proposed that the AI has a crucial role in intentional self-generated action and suggested that this region could evaluate self-generated actions regarding their affective value, thereby guiding learning and future action selection. 
We propose that the monitoring of action and error agency is not only crucial for learning, but it also critically determines emotional states associated with different action outcomes (cf. Koban et al., 2013a). In addition to action correctness and social relationship, the perception of agency may determine whether we feel guilty or angry following errors, and whether we experience pride or envy after positive action outcomes. Thus, the AI is well placed to integrate information about action outcomes not only with affective and social context factors, but also with the perception of self-agency (Brass and Haggard, 2010; Koban et al., 2013a). Integration of outcomes with agency and social context information may lead to error awareness (Ullsperger et al., 2010) and to the generation of more complex specific feeling states that are associated with different action outcomes (Craig, 2009; Koban et al., 2013a; Koban et al., 2012b).

\subsection{Different levels of integration within the dMFC vs. AI}

Although speculative at this stage, the different findings reviewed here above regarding interactions between action monitoring, affective processes, and social factors support the view that the dMFC and AI each contributes to bring together different and complementary sources of information during the monitoring of actions (see Figure 3). In this view, positive vs. negative affective value of actions are determined quickly and automatically by the dACC/dMFC in conjunction with specific striatal and limbic structures (Fiorillo et al., 2003; Holroyd and Coles, 2002a). This is in line with theoretical accounts, which have suggested that the dACC/dMFC primarily operates as a monitor of conflicts, errors, and more generally, differences between actual and predicted or desired states, which require adjustments in cognitive control (Alexander and Brown, 2011; Botvinick et al., 2001; Holroyd and Coles, 2002a; Shackman et al., 2011; 
Shenhav et al., 2013). Action monitoring in dACC/dMFC is sensitive to motivational factors such as perceived costs and reinforcement values (Shackman et al., 2011; Shenhav et al., 2013) and consequently an intrinsically affective evaluation (Aarts et al., 2012; Aarts et al., 2013; Proudfit et al., 2013), which may be enhanced in anxiety and other affective disorders (Aarts and Pourtois, 2010; Moser et al., 2013; Proudfit et al., 2013).

By comparison, we propose that the AI uses this information in a second and parallel stage of action monitoring and integrates information about action correctness from the dMFC/dACC with action agency, and into a broader context of emotional and social factors (Frith et al., 2008; Koban et al., 2013a; Seth et al., 2011). This second integrative step may generate the Pe and feedback-P300 components and be associated with error awareness (see Craig, 2009; Dhar et al., 2011; Nieuwenhuis et al., 2001; Ullsperger et al., 2010). Given the important role of AI in emotions and in representing others' feeling states (Engen and Singer, 2013; Kober et al., 2008; Lindquist et al., 2012; Singer et al., 2009), activity of this region during action monitoring may reflect the generation of complex and situation-specific emotions (e.g. feelings of guilt when one's errors cause pain to close others, Koban et al., 2013a).

Recent findings on error monitoring in individuals with psychopathy and unemotionalcallous traits support this idea. Psychopathic personality is characterized by ongoing antisocial behavior, lack or empathy or remorse, and difficulties in inhibition and behavioral control, which are paralleled by widespread abnormalities in prefrontal cortex (Anderson and Kiehl, 2012; Koenigs, 2012). Recent studies demonstrated that in psychopathy, the AI is altered both structurally (Aoki et al., 2013) as well as functionally in response to others' pain (Decety et al., 2013). In parallel, ERP results showed that psychopathy reduces the size of the Pe component selectively, while leaving the ERN and post-error adjustment in behavior intact (Brazil et al., 
2009). This indicates that psychopathy may be associated with a specific alteration of the integration processes with affective, social, and agency factors during action monitoring, for which the AI likely plays a predominant role (Brass and Haggard, 2010; Koban et al., 2013a; Ullsperger et al., 2010).

Although preliminary and awaiting future empirical validation, our framework may help to delineate the respective functions of two major anatomical components of action monitoring. Both dMFC/dACC and AI may contribute to trigger changes in adaptive control through modulation of interconnected fronto-parietal areas (Chang et al., 2013) at different latencies following action onset. Speculatively, we propose that the dACC might be more important for automatic action monitoring, whereas the AI could be crucial for generating emotionally more complex states, which could serve as a basis for more deliberate and conscious efforts to adjust behavior in a more flexible way (Figure 3). Additional imaging and neurophysiological studies are needed to test this hypothesis and to confirm the complementary and dissociable functions of $\mathrm{AI}$ and $\mathrm{dMFC} / \mathrm{dACC}$ during action monitoring.

-- please insert Figure 3 about here --

\subsection{Outstanding questions and future directions}

Although this review gives an overview of the potential roles of different brain regions involved in social-affective effects on action monitoring, several important questions remain unanswered at this stage. First, term-based meta-analysis provides information about common activations across a large number of studies (and by extension hundreds of individual subjects), but it is not clear, whether overlapping activations for error monitoring and social-affective 
processing would also be found at the individual level. More importantly, conjunction of activity does not equal functional convergence or involvement of the same neural populations, and more intracranial electrophysiological studies in patients and animals are needed to investigate the functional relationship of different processes in $\mathrm{AI}$ and $\mathrm{dMFC}$.

As a second limitation of the automated meta-analytic approach, it is not clear whether $\mathrm{dMFC}$ and AI/IFG activations reported in imaging studies on social cognition or emotion reflect specifically social or affective processes. More basic mechanisms or qualities such as effort or arousal could be common to emotion, social cognition, and action monitoring tasks (Kool et al., 2010; McGuire and Botvinick, 2010). DMFC and AI/IFG are among the most frequently activated brain areas across a large number of experimental paradigms and research questions (cf. Behrens et al., 2013; Craig, 2009; Shackman et al., 2011). It appears therefore unlikely that they would be specific for emotions, social cognition, and/or error processing. Yet, this fact does not contradict the hypothesis that these areas could be critical (even if not necessarily selective) for interactions between error/conflict monitoring and affective or social factors. Given the costliness of neural computations, it is doubtful that brain areas just get activated as "byproducts". On the contrary, frequently activated areas such as AI and dMFC often constitute important hubs within and between different functional networks, and could thereby link different processing domains or have functionally integrative properties (Achard et al., 2006; Buckner et al., 2009; Bullmore and Sporns, 2009). Again, lesion studies in patients and additional mechanistic work in nonhuman primates might help to illuminate the roles of AI and dMFC in the interplay between social-affective and action outcome processing.

Third, little is known about the developmental trajectories of the contributions of AI and dMFC/dACC to action monitoring, especially their specialization during infancy and 
adolescence (Modha and Singh, 2010). Gaining additional information about the development and maturation of these two regions will yield a better understanding of their roles and functions during action monitoring at the adult age. Further, specific developmental trajectories could also inform us about the origin of abnormal or pathological conditions (e.g. psychopathy) that may arise partially because of functional or structural alterations in this network (Anderson and Kiehl, 2012; Bernhardt et al., 2013; Brazil et al., 2009; Brazil et al., 2011). In this respect, recent advancements in developmental cognitive neuroscience and neuroimaging promise to lead to significant breakthroughs in our understanding of the complex interplay between affect, social cognition, and action monitoring (Crone and Richard Ridderinkhof, 2011).

Fourth, given the extensive repertoire and malleability of socially-bound emotions in humans and their links to core action monitoring processes, it is important to develop new experimental methods that will enable studying the emergence of specific social emotions in the laboratory (Chang and Koban, 2013), as well as characterizing their neurobiological underpinnings (Barrett et al., 2007). New EEG or fMRI studies investigating action monitoring in social settings would allow exploration of changes in action monitoring brain processes in the medial frontal cortex and $\mathrm{AI}$ and $\mathrm{dMFC}$, as well as the potential impairments in those processes in different psychopathologies, including social and generalized anxiety, autism, and psychopathy.

Finally, because these two regions are likely influenced dynamically by several neurotransmitters systems during action monitoring (Cools, 2011; Cools et al., 2008; de Bruijn et al., 2004; Denk et al., 2005), neuroimaging studies combining pharmacological manipulations may provide a unique avenue for future research in order to delineate the nature and extent of interaction effects with social and emotional processes taking place in each of these two hubs. 
Likewise, recent advancements in imaging genetics will provide important insights into how this complex performance monitoring brain machinery is shaped not only by situational factors related to the current affective state or social context, but also by genetic variations (Sallet and Rushworth, 2009).

\section{Acknowledgements}

This work was supported by a post-doctoral fellowship from the Swiss National Science Foundation to LK (PBGEP1_142252), and by grants from the European Research Council (Starting Grant \#200758) and by the Belgian Science Policy, Interuniversity Attraction Poles program (P7/11) to GP. We thank Patrik Vuilleumier for his continuous support, as well as Alex Shackman and a second, anonymous reviewer for their helpful comments. 


\section{References}

Aarts, K., De Houwer, J., Pourtois, G., 2012. Evidence for the automatic evaluation of selfgenerated actions. Cognition 124, 117-127.

Aarts, K., De Houwer, J., Pourtois, G., 2013. Erroneous and Correct Actions Have a Different Affective Valence: Evidence From ERPs. Emotion (Washington, D.C.).

Aarts, K., Pourtois, G., 2010. Anxiety not only increases, but also alters early error-monitoring functions. Cognitive, Affective \& Behavioral Neuroscience 10, 479-492.

Aarts, K., Pourtois, G., 2012. Anxiety disrupts the evaluative component of performance monitoring: An ERP study. Neuropsychologia 50, 1286-1296.

Aarts, K., Vanderhasselt, M.A., Otte, G., Baeken, C., Pourtois, G., in press. Electrical brain imaging reveals the expression and timing of altered error monitoring functions in major depression. Journal of Abnormal Psychology.

Achard, S., Salvador, R., Whitcher, B., Suckling, J., Bullmore, E., 2006. A Resilient, LowFrequency, Small-World Human Brain Functional Network with Highly Connected Association Cortical Hubs. The Journal of Neuroscience 26, 63-72.

Alexander, W.H., Brown, J.W., 2011. Medial prefrontal cortex as an action-outcome predictor. Nature Neuroscience 14, 1338-1344.

Anderson, A.K., Phelps, E.A., 2000. Expression without recognition: contributions of the human amygdala to emotional communication. Psychological Science 11, 106-111.

Anderson, N.E., Kiehl, K.A., 2012. The psychopath magnetized: insights from brain imaging. Trends in cognitive sciences $16,52-60$.

Aoki, Y., Inokuchi, R., Nakao, T., Yamasue, H., 2013. Neural bases of antisocial behavior: a voxel-based meta-analysis Running title: Antisocial brain: a meta-analysis of VBM. Social cognitive and affective neuroscience.

Barbas, H., Zikopoulos, B., Timbie, C., 2011. Sensory Pathways and Emotional Context for Action in Primate Prefrontal Cortex. Biological Psychiatry 69, 1133-1139.

Barrett, L.F., Mesquita, B., Ochsner, K.N., Gross, J.J., 2007. The experience of emotion. Annual review of psychology 58.

Bates, A.T., Patel, T.P., Liddle, P.F., 2005. External behavior monitoring mirrors internal behavior monitoring - Error-related negativity for observed errors. Journal of Psychophysiology 19, 281-288.

Bault, N., Coricelli, G., Rustichini, A., 2008. Interdependent utilities: How social ranking affects choice behavior. PLoS ONE 3, e3477-e3477.

Bault, N., Joffily, M., Rustichini, A., Coricelli, G., 2011. Medial prefrontal cortex and striatum mediate the influence of social comparison on the decision process. Proceedings of the National Academy of Sciences 108, 16044-16049.

Bediou, B., Koban, L., Rosset, S., Pourtois, G., Sander, D., 2012. Delayed monitoring of accuracy errors compared to commission errors in ACC. NeuroImage 60, 1925-1936.

Behrens, T.E.J., Fox, P., Laird, A., Smith, S.M., 2013. What is the most interesting part of the brain? Trends in cognitive sciences 17, 2-4.

Bellebaum, C., Kobza, S., Thiele, S., Daum, I., 2010. It Was Not MY Fault: Event-Related Brain Potentials in Active and Observational Learning from Feedback. Cerebral Cortex 20, 2874-2883. Bernhardt, B.C., Valk, S.L., Silani, G., Bird, G., Frith, U., Singer, T., 2013. Selective Disruption of Sociocognitive Structural Brain Networks in Autism and Alexithymia. Cerebral Cortex. 
Blakemore, S.J., Wolpert, D.M., Frith, C.D., 1998. Central cancellation of self-produced tickle sensation. Nature Neuroscience 1, 635-640.

Boksem, M.a.S., Kostermans, E., De Cremer, D., 2011a. Failing where others have succeeded: Medial Frontal Negativity tracks failure in a social context. Psychophysiology 48, 973-979.

Boksem, M.A.S., Ruys, K.I., Aarts, H., 2011b. Facing disapproval : Performance monitoring in a social context Facing disapproval : Performance monitoring.

Boksem, M.a.S., Tops, M., Wester, A.E., Meijman, T.F., Lorist, M.M., 2006. Error-related ERP components and individual differences in punishment and reward sensitivity. Brain research 1101, 92-101.

Botvinick, M., Nystrom, L.E., Fissell, K., Carter, C.S., Cohen, J.D., 1999. Conflict monitoring versus selection-for-action in anterior cingulate cortex. Nature 402, 179-181.

Botvinick, M.M., 2007. Conflict monitoring and decision making: reconciling two perspectives on anterior cingulate function. Cognitive, Affective \& Behavioral Neuroscience 7, 356-366.

Botvinick, M.M., Braver, T.S., Barch, D.M., Carter, C.S., Cohen, J.D., 2001. Conflict monitoring and cognitive control. Psychological Review 108, 624-652.

Brass, M., Haggard, P., 2010. The hidden side of intentional action: the role of the anterior insular cortex. Brain Structure \& Function 214, 603-610.

Brass, M., Ruby, P., Spengler, S., 2009. Inhibition of imitative behaviour and social cognition. Philosophical Transactions of the Royal Society of London. Series B, Biological Sciences 364, 2359-2367.

Brazil, I.A., de Bruijn, E.R.A., Bulten, B.H., von Borries, A.K.L., van Lankveld, J.J.D.M., Buitelaar, J.K., Verkes, R.J., 2009. Early and late components of error monitoring in violent offenders with psychopathy. Biological Psychiatry 65, 137-143.

Brazil, I.A., Mars, R.B., Bulten, B.H., Buitelaar, J.K., Verkes, R.J., De Bruijn, E.R.A., 2011. A neurophysiological dissociation between monitoring one's own and others' actions in psychopathy. Biological Psychiatry 69, 693-699.

Buckner, R.L., Sepulcre, J., Talukdar, T., Krienen, F.M., Liu, H., Hedden, T., Andrews-Hanna, J.R., Sperling, R.A., Johnson, K.A., 2009. Cortical Hubs Revealed by Intrinsic Functional Connectivity: Mapping, Assessment of Stability, and Relation to Alzheimer's Disease. The Journal of Neuroscience 29, 1860-1873.

Bullmore, E., Sporns, O., 2009. Complex brain networks: graph theoretical analysis of structural and functional systems. Nature Reviews. Neuroscience 10, 186-198.

Bush, Luu, Posner, 2000a. Cognitive and emotional influences in anterior cingulate cortex. Trends in Cognitive Sciences 4, 215-222.

Bush, G., Luu, P., Posner, M.I., 2000b. Cognitive and emotional influences in anterior cingulate cortex. Trends in Cognitive Sciences 4, 215-222.

Bzdok, D., Langner, R., Schilbach, L., Engemann, D.A., Laird, A.R., Fox, P.T., Eickhoff, S.B., 2013. Segregation of the human medial prefrontal cortex in social cognition. Frontiers in human neuroscience 7.

Carp, J., Halenar, M.J., Quandt, L.C., Sklar, A., Compton, R.J., 2009. Perceived similarity and neural mirroring: Evidence from vicarious error processing. Social Neuroscience 4, 85-96.

Carrasco, M., Larosa, C., Hong, C., Gehring, W.J., Hanna, G., 2006. Error-related brain activity in unaffected siblings of children with obsessive-compulsive disorder. Methods, 2006-2006.

Carter, C.S., 1998. Anterior Cingulate Cortex, Error Detection, and the Online Monitoring of Performance. Science 280, 747-749. 
Carter, C.S., Braver, T.S., Barch, D.M., Botvinick, M.M., Noll, D., Cohen, J.D., 1998. Anterior cingulate cortex, error detection, and the online monitoring of performance. Science 280, 747749.

Carver, C.S., White, T.L., 1994. Behavioral inhibition, behavioral activation, and affective responses to impending reward and punishment: The BIS/BAS scales. Journal of personality and social psychology 67, 319-333.

Cavanagh, J.F., Zambrano-Vazquez, L., Allen, J.J., 2012. Theta lingua franca: a common midfrontal substrate for action monitoring processes. Psychophysiology 49, 220-238.

Chambon, V., Wenke, D., Fleming, S.M., Prinz, W., Haggard, P., 2012. An Online Neural Substrate for Sense of Agency. Cerebral cortex (New York, N.Y.: 1991).

Chang, L.J., Koban, L., 2013. Modeling emotion and learning of norms in social interactions. The Journal of neuroscience: the official journal of the Society for Neuroscience 33, 7615-7617.

Chang, L.J., Smith, A., Dufwenberg, M., Sanfey, A.G., 2011. Triangulating the neural, psychological, and economic bases of guilt aversion. Neuron 70, 560-572.

Chang, L.J., Yarkoni, T., Khaw, M.W., Sanfey, A.G., 2013. Decoding the role of the insula in human cognition: functional parcellation and large-scale reverse inference. Cereb Cortex 23, 739-749.

Cohen, J.D., Aston-Jones, G., Gilzenrat, M.S., 2004. A systems-level perspective on attention and cognitive control: Guided activation, adaptive gating, conflict monitoring, and exploitation vs. exploration, in: Posner, M.I. (Ed.), Cognitive Neuroscience of Attention. Guilford Press, New York, pp. 71-90.

Cohen, M.X., 2011. Error-related medial frontal theta activity predicts cingulate-related structural connectivity. NeuroImage 55, 1373-1383.

Compton, R.J., Hofheimer, J., Kazinka, R., 2013. Stress regulation and cognitive control: evidence relating cortisol reactivity and neural responses to errors. Cognitive, affective \& behavioral neuroscience 13, 152-163.

Cools, R., 2011. Dopaminergic control of the striatum for high-level cognition. Current opinion in neurobiology 21, 402-407.

Cools, R., Roberts, A.C., Robbins, T.W., 2008. Serotoninergic regulation of emotional and behavioural control processes. Trends in cognitive sciences 12, 31-40.

Coricelli, G., Critchley, H.D., Joffily, M., O'Doherty, J.P., Sirigu, A., Dolan, R.J., 2005. Regret and its avoidance: a neuroimaging study of choice behavior. Nature Neuroscience 8, 1255-1262.

Coricelli, G., Rustichini, A., 2010. Counterfactual thinking and emotions: regret and envy learning. Philosophical Transactions of the Royal Society of London. Series B, Biological Sciences 365, 241-247.

Craig, A.D., 2009. How do you feel--now? The anterior insula and human awareness. Nat Rev Neurosci 10, 59-70.

Critchley, H.D., Wiens, S., Rotshtein, P., Ohman, A., Dolan, R.J., 2004. Neural systems supporting interoceptive awareness. Nature Neuroscience 7, 189-195.

Crone, E.A., Richard Ridderinkhof, K., 2011. The developing brain: from theory to neuroimaging and back. Developmental Cognitive Neuroscience 1, 101-109.

Danielmeier, C., Eichele, T., Forstmann, B.U., Tittgemeyer, M., Ullsperger, M., 2011. Posterior medial frontal cortex activity predicts post-error adaptations in task-related visual and motor areas. Journal of Neuroscience 31, 1780-1789.

Danielmeier, C., Ullsperger, M., 2011. Post-error adjustments. Frontiers in Cognition 2, 233-233. 
David, N., Bewernick, B.H., Cohen, M.X., Newen, A., Lux, S., Fink, G.R., Shah, N.J., Vogeley, K., 2006. Neural representations of self versus other: visual-spatial perspective taking and agency in a virtual ball-tossing game. Journal of Cognitive Neuroscience 18, 898-910.

Davis, M., Whalen, P.J., 2001. The amygdala: vigilance and emotion. Molecular psychiatry 6, 13-34.

de Bruijn, E.R.A., de Lange, F.P., von Cramon, D.Y., Ullsperger, M., 2009. When Errors Are Rewarding. The Journal of Neuroscience 29, 12183-12186.

de Bruijn, E.R.A., Hulstijn, W., Verkes, R.J., Ruigt, G.S.F., Sabbe, B.G.C., 2004. Drug-induced stimulation and suppression of action monitoring in healthy volunteers. Psychopharmacology 177, 151-160.

de Bruijn, E.R.A., Mars, R.B., Bekkering, H., Coles, M.G.H., 2011. Your mistake is my mistake ... or is it? Behavioural adjustments following own and observed actions in cooperative and competitive contexts. Quarterly Journal of Experimental Psychology, 1-9.

de Bruijn, E.R.A., von Rhein, D.T., 2012. Is Your Error My Concern? An Event-Related Potential Study on Own and Observed Error Detection in Cooperation and Competition. Frontiers in Neuroscience 6, 8.

De Pascalis, V., Varriale, V., D'Antuono, L., 2010. Event-related components of the punishment and reward sensitivity. Clinical Neurophysiology 121, 60-76.

Debener, S., Ullsperger, M., Siegel, M., Fiehler, K., von Cramon, D.Y., Engel, A.K., 2005. Trialby-trial coupling of concurrent electroencephalogram and functional magnetic resonance imaging identifies the dynamics of performance monitoring. The Journal of Neuroscience 25, 11730-11737.

Decety, J., Skelly, L.R., Kiehl, K.A., 2013. Brain Response to Empathy-Eliciting Scenarios Involving Pain in Incarcerated Individuals With Psychopathy. JAMA Psychiatry, 1-8.

Dehaene, S., Posner, M.I., Tucker, D.M., 1994. Localization of a Neural System for ErrorDetection and Compensation. Psychological Science 5, 303-305.

Delgado, M.R., Nystrom, L.E., Fissell, C., Noll, D.C., Fiez, J.A., 2000. Tracking the hemodynamic responses to reward and punishment in the striatum. Journal of Neurophysiology 84, 3072-3077.

Denk, F., Walton, M.E., Jennings, K.A., Sharp, T., Rushworth, M.F.S., Bannerman, D.M., 2005. Differential involvement of serotonin and dopamine systems in cost-benefit decisions about delay or effort. Psychopharmacology 179, 587-596.

Desmet, C., Fias, W., Hartstra, E., Brass, M., 2011. Errors and Conflict at the Task Level and the Response Level. The Journal of Neuroscience 31, 1366-1374.

Devinsky, O., Morrell, M.J., Vogt, B.A., others, 1995. Contributions of anterior cingulate cortex to behaviour. BRAIN 118, 279-306.

Dhar, M., Wiersema, J.R., Pourtois, G., 2011. Cascade of neural events leading from error commission to subsequent awareness revealed using EEG source imaging. PLoS ONE 6, e19578-e19578.

Doñamayor, N., Heilbronner, U., Münte, T.F., 2011. Coupling electrophysiological and hemodynamic responses to errors. Human Brain Mapping.

Dreisbach, G., Fischer, R., 2012. Conflicts as aversive signals. Brain and Cognition 78, 94-98.

Drevets, W.C., Raichle, M.E., 1998. Reciprocal suppression of regional cerebral blood flow during emotional versus higher cognitive processes: Implications for interactions between emotion and cognition. Cognition and Emotion 12, 353-385. 
Endrass, T., Franke, C., Kathmann, N., 2005. Error Awareness in a Saccade Countermanding Task. Journal of Psychophysiology 19, 275-280.

Endrass, T., Klawohn, J., Schuster, F., Kathmann, N., 2008. Overactive performance monitoring in obsessive-compulsive disorder: ERP evidence from correct and erroneous reactions. Neuropsychologia 46, 1877-1887.

Endrass, T., Reuter, B., Kathmann, N., 2007. ERP correlates of conscious error recognition: aware and unaware errors in an antisaccade task. European Journal of Neuroscience 26, 17141720.

Endrass, T., Schuermann, B., Kaufmann, C., Spielberg, R., Kniesche, R., Kathmann, N., 2010. Performance monitoring and error significance in patients with obsessive-compulsive disorder. Biol Psychol 84, 257-263.

Engen, H.G., Singer, T., 2013. Empathy circuits. Curr Opin Neurobiol 23, 275-282.

Eppinger, B., Kray, J., Mock, B., Mecklinger, A., 2008. Better or worse than expected? Aging, learning, and the ERN. Neuropsychologia 46, 521-539.

Etkin, A., 2010. Functional neuroanatomy of anxiety: a neural circuit perspective. Current Topics in Behavioral Neurosciences 2, 251-277.

Etkin, A., Egner, T., Kalisch, R., 2011. Emotional processing in anterior cingulate and medial prefrontal cortex. Trends in Cognitive Sciences 15, 85-93.

Etkin, A., Wager, T.D., 2007. Functional Neuroimaging of Anxiety: A Meta-Analysis of Emotional Processing in PTSD, Social Anxiety Disorder, and Specific Phobia. Am J Psychiatry 164, 1476-1488.

Fadiga, L., Craighero, L., Olivier, E., 2005. Human motor cortex excitability during the perception of others' action. Curr Opin Neurobiol 15, 213-218.

Falkenstein, M., Hoormann, J., Christ, S., Hohnsbein, J., 2000. ERP components on reaction errors and their functional significance: a tutorial. Biological Psychology 51, 87-107.

Farrer, C., Frey, S.H., Van Horn, J.D., Tunik, E., Turk, D., Inati, S., Grafton, S.T., 2008. The angular gyrus computes action awareness representations. Cerebral Cortex 18, 254-261.

Farrer, C., Frith, C.D., 2002. Experiencing Oneself vs Another Person as Being the Cause of an Action: The Neural Correlates of the Experience of Agency. NeuroImage 15, 596-603.

Fazio, R.H., Sanbonmatsu, D.M., Powell, M.C., Kardes, F.R., 1986. On the Automatic Activation of Attitudes. Journal of Personality and Social Psychology 50, 229-238.

Fiorillo, C.D., Tobler, P.N., Schultz, W., 2003. Discrete Coding of Reward Probability and Uncertainty by Dopamine Neurons. Science 299, 1898-1902.

Foti, D., Hajcak, G., 2009. Depression and reduced sensitivity to non-rewards versus rewards: Evidence from event-related potentials. Biological Psychology 81, 1-8.

Frank, M.J., Woroch, B.S., Curran, T., 2005. Error-related negativity predicts reinforcement learning and conflict biases. Neuron 47, 495-501.

Frith, C.D., Singer, T., B, P.T.R.S., 2008. The role of social cognition in decision making The role of social cognition in decision making. Society, 3875-3886.

Fukushima, H., Hiraki, K., 2009. Whose loss is it? Human electrophysiological correlates of non-self reward processing. Social Neuroscience 4, 261-261.

Gallagher, S., 2000. Philosophical conceptions of the self: implications for cognitive science. Trends in Cognitive Sciences 4, 14-21.

Gallese, V., Keysers, C., Rizzolatti, G., 2004. A unifying view of the basis of social cognition. Trends in Cognitive Sciences 8, 396-403. 
Garavan, H., Ross, T.J., Kaufman, J., Stein, E.A., 2003. A midline dissociation between errorprocessing and response-conflict monitoring RID B-7469-2008 RID C-7349-2008. NeuroImage 20, 1132-1139.

Gehring, W.J., Fencsik, D.E., 2001. Functions of the medial frontal cortex in the processing of conflict and errors. The Journal of neuroscience : the official journal of the Society for Neuroscience 21, 9430-9437.

Gehring, W.J., Himle, J., Nisenson, L.G., 2000. Action-monitoring dysfunction in obsessivecompulsive disorder. Psychological Science 11, 1-6.

Gehring, W.J., Willoughby, A.R., 2002. The medial frontal cortex and the rapid processing of monetary gains and losses. Science 295, 2279-2282.

Gentsch, A., Ullsperger, P., Ullsperger, M., 2009. Dissociable medial frontal negativities from a common monitoring system for self- and externally caused failure of goal achievement. NeuroImage 47, 2023-2030.

Gentsch, K., Grandjean, D., Scherer, K.R., 2013. Temporal dynamics of event-related potentials related to goal conduciveness and power appraisals. Psychophysiology 50, 1010-1022.

Georgieff, N., Jeannerod, M., 1998. Beyond consciousness of external reality: a "who" system for consciousness of action and self-consciousness. Consciousness and Cognition 7, 465-477.

Gratton, G., Coles, M.G., Donchin, E., 1992. Optimizing the use of information: strategic control of activation of responses. Journal of Experimental Psychology: General 121, 480-480.

Gray, J.R., Braver, T.S., Raichle, M.E., 2002. Integration of Emotion and Cognition in the Lateral Prefrontal Cortex. Proceedings of the National Academy of Sciences 99, 4115-4120.

Gu, R., Huang, Y.-X., Luo, Y.-J., 2010. Anxiety and feedback negativity. Psychophysiology.

Gu, X., Liu, X., Van Dam, N.T., Hof, P.R., Fan, J., 2012. Cognition-Emotion Integration in the Anterior Insular Cortex. Cerebral Cortex.

Hajcak, G., Foti, D., 2008. Errors are aversive: defensive motivation and the error-related negativity. Psychological Science 19, 103-108.

Hajcak, G., McDonald, N., Simons, R.F., 2003a. Anxiety and error-related brain activity. Biological Psychology 64, 77-90.

Hajcak, G., McDonald, N., Simons, R.F., 2003b. To err is autonomic: Error-related brain potentials, ANS activity, and post-error compensatory behavior. Psychophysiology 40, 895-903.

Hajcak, G., Simons, R.F., 2002. Error-related brain activity in obsessive-compulsive undergraduates. Psychiatry Research 110, 63-72.

Heldmann, M., Rüsseler, J., Münte, T.F., 2008. Internal and external information in error processing. BMC Neuroscience 9, 33-33.

Herrmann, M.J., Römmler, J., Ehlis, A.-C., Heidrich, A., Fallgatter, A.J., 2004. Source localization (LORETA) of the error-related-negativity (ERN/Ne) and positivity $(\mathrm{Pe})$. Brain Research. Cognitive Brain Research 20, 294-299.

Hirsh, J.B., Inzlicht, M., 2008. The Devil You Know Neuroticism Predicts Neural Response to Uncertainty. Psychological Science 19, 962-967.

Holland, P.C., Gallagher, M., 2006. Different roles for amygdala central nucleus and substantia innominata in the surprise-induced enhancement of learning. The Journal of neuroscience: the official journal of the Society for Neuroscience 26, 3791-3797.

Holroyd, C.B., Coles, M.G., 2002a. The neural basis of human error processing: reinforcement learning, dopamine, and the error-related negativity. Psychol Rev 109, 679-709.

Holroyd, C.B., Coles, M.G.H., 2002b. The neural basis of human error processing: reinforcement learning, dopamine, and the error-related negativity. Psychological Review 109, 679-709. 
Holroyd, C.B., Yeung, N., 2012. Motivation of extended behaviors by anterior cingulate cortex. Trends in cognitive sciences 16, 122-128.

Itagaki, S., 2008. Self-relevant criteria determine the evaluation of outcomes induced by others. General Systems 19, 383-387.

Johannes, S., Wieringa, B.M., Nager, W., Rada, D., Dengler, R., Emrich, H.M., Munte, T.F., Dietrich, D.E., 2001. Discrepant target detection and action monitoring in obsessive-compulsive disorder. Psychiat Res-Neuroim 108, 101-110.

Kang, S.K., Hirsh, J.B., 2010. Your mistakes are mine: Self-other overlap predicts neural response to observed errors. Journal of Experimental Social.

Kashtelyan, V., Tobia, S.C., Burton, A.C., Bryden, D.W., Roesch, M.R., 2012. Basolateral amygdala encodes upcoming errors but not response conflict. The European journal of neuroscience 35, 952-959.

Kelley, W.M., Macrae, C.N., Wyland, C.L., Caglar, S., Inati, S., Heatherton, T.F., 2002. Finding the self? An event-related fMRI study. Journal of Cognitive Neuroscience 14, 785-794.

Kerns, J.G., Cohen, J.D., MacDonald, A.W., 3rd, Cho, R.Y., Stenger, V.A., Carter, C.S., 2004. Anterior cingulate conflict monitoring and adjustments in control. Science 303, 1023-1026.

Keysers, C., Gazzola, V., 2006. Towards a unifying neural theory of social cognition. Progress in Brain Research 156, 379-401.

Kiehl, K.A., Liddle, P.F., Hopfinger, J.B., 2000. Error processing and the rostral anterior cingulate: An event-related fMRI study. Psychophysiology 37, 216-223.

Kim, M.J., Gee, D.G., Loucks, R.A., Davis, F.C., Whalen, P.J., 2011. Anxiety dissociates dorsal and ventral medial prefrontal cortex functional connectivity with the amygdala at rest. Cerebral cortex 21, 1667-1673.

King, J.A., Korb, F.M., von Cramon, D.Y., Ullsperger, M., 2010. Post-error behavioral adjustments are facilitated by activation and suppression of task-relevant and task-irrelevant information processing. The Journal of Neuroscience: The Official Journal of the Society for Neuroscience 30, 12759-12769.

Klein, T.A., Endrass, T., Kathmann, N., Neumann, J., von Cramon, D.Y., Ullsperger, M., 2007. Neural correlates of error awareness. NeuroImage 34, 1774-1781.

Koban, L., Brass, M., Lynn, M.T., Pourtois, G., 2012a. Placebo Analgesia Affects Brain Correlates of Error Processing. PLoS ONE 7, e49784-e49784.

Koban, L., Corradi-Dell Acqua, C., Vuilleumier, P., 2013a. Integration of Error Agency and Representation of Others' Pain in the Anterior Insula. Journal of Cognitive Neuroscience 25, 258-272.

Koban, L., Pichon, S., Vuilleumier, P., 2013b. Responses of medial and ventrolateral prefrontal cortex to interpersonal conflict for resources. Social Cognitive and Affective Neuroscience.

Koban, L., Pourtois, G., Bediou, B., Vuilleumier, P., 2012b. Effects of social context and predictive relevance on action outcome monitoring. Cognitive, Affective \& Behavioral Neuroscience 12, 460-478.

Koban, L., Pourtois, G., Vocat, R., Vuilleumier, P., 2010. When your errors make me lose or win: event-related potentials to observed errors of cooperators and competitors. Social Neuroscience 5, 360-374.

Kober, H., Barrett, L.F., Joseph, J., Bliss-Moreau, E., Lindquist, K., Wager, T.D., 2008. Functional grouping and cortical-subcortical interactions in emotion: a meta-analysis of neuroimaging studies. NeuroImage 42, 998-1031. 
Koenigs, M., 2012. The role of prefrontal cortex in psychopathy. Reviews in the neurosciences 23, 253-262.

Kool, W., McGuire, J.T., Rosen, Z.B., Botvinick, M.M., 2010. Decision making and the avoidance of cognitive demand. Journal of Experimental Psychology: General 139, 665-665.

Krueger, R.F., McGue, M., Iacono, W.G., 2001. The higher-order structure of common DSM mental disorders: internalization, externalization, and their connections to personality. Personality and Individual Differences 30, 1245-1259.

LaBar, K.S., Gatenby, J.C., Gore, J.C., LeDoux, J.E., Phelps, E.A., 1998. Human amygdala activation during conditioned fear acquisition and extinction: a mixed-trial fMRI study. Neuron 20, 937-945.

Lamm, C., Decety, J., Singer, T., 2011. Meta-analytic evidence for common and distinct neural networks associated with directly experienced pain and empathy for pain. NeuroImage 54, 24922502.

Leng, Y., Zhou, X., 2010. Modulation of the brain activity in outcome evaluation by interpersonal relationship: an ERP study. Neuropsychologia 48, 448-455.

Lindquist, K.a., Wager, T.D., Kober, H., Bliss-Moreau, E., Barrett, L.F., 2012. The brain basis of emotion: a meta-analytic review. The Behavioral and brain sciences 35, 121-143.

Luu, P., Collins, P., Tucker, D.M., 2000. Mood, personality, and self-monitoring: Negative affect and emotionality in relation to frontal lobe mechanisms of error monitoring. J Exp Psychol Gen 129, 43-60.

MacDonald, A.W., Cohen, J.D., Stenger, V.A., Carter, C.S., 2000. Dissociating the role of the dorsolateral prefrontal and anterior cingulate cortex in cognitive control. Science 288, 18351838.

Marco-Pallares, J., Kramer, U., Strehl, S., Schroder, A., Munte, T., 2010. When decisions of others matter to me: an electrophysiological analysis. BMC Neuroscience 11, 86-86.

McGuire, J.T., Botvinick, M.M., 2010. Prefrontal cortex, cognitive control, and the registration of decision costs. Proceedings of the National Academy of Sciences 107.

Menon, V., Adleman, N.E., White, C.D., Glover, G.H., Reiss, A.L., 2001. Error-related brain activation during a Go/NoGo response inhibition task. Human Brain Mapping 12, 131-143.

Miele, D.B., Wager, T.D., Mitchell, J.P., Metcalfe, J., 2011. Dissociating Neural Correlates of Action Monitoring and Metacognition of Agency. Journal of Cognitive Neuroscience.

Mies, G.W., van der Veen, F.M., Tulen, J.H.M., Birkenhäger, T.K., Hengeveld, M.W., van der Molen, M.W., 2011. Drug-free patients with major depression show an increased electrophysiological response to valid and invalid feedback. Psychological medicine 41, 25152525.

Miltner, W.H.R., Brauer, J., Hecht, H., Trippe, R., Coles, M.G.H., 2004. Parallel brain activity for self-generated and observed errors., in: Ullsperger, M., Falkenstein, M. (Eds.), Errors, conflicts, and the Brain. Current Opinions on Performance Monitoring. MPI of Cognitive Neuroscience, Leipzig, pp. 124-129.

Miltner, W.H.R., Braun, C.H., Coles, M.G.H., 1997. Event-Related Brain Potentials Following Incorrect Feedback in a Time-Estimation Task: Evidence for a "Generic" Neural System for Error Detection. Journal of Cognitive Neuroscience 9, 788-798.

Mitchell, J.P., Banaji, M.R., Macrae, C.N., 2005. The link between social cognition and selfreferential thought in the medial prefrontal cortex. Journal of Cognitive Neuroscience 17, 13061315. 
Mobbs, D., Yu, R., Meyer, M., Passamonti, L., Seymour, B., Calder, A.J., Schweizer, S., Frith, C.D., Dalgleish, T., 2009. A Key Role for Similarity in Vicarious Reward. Science 324, 900-900. Modha, D.S., Singh, R., 2010. Network architecture of the long-distance pathways in the macaque brain. Proc Natl Acad Sci U S A 107, 13485-13490.

Moser, J.S., Moran, T.P., Schroder, H.S., Donnellan, M.B., Yeung, N., 2013. On the relationship between anxiety and error monitoring: a meta-analysis and conceptual framework. Frontiers in human neuroscience 7.

Nee, D.E., Kastner, S., Brown, J.W., 2011. Functional heterogeneity of conflict, error, taskswitching, and unexpectedness effects within medial prefrontal cortex. Neuroimage 54, 528-540. Nee, D.E., Wager, T.D., Jonides, J., 2007. Interference resolution: insights from a meta-analysis of neuroimaging tasks. Cognitive, Affective \& Behavioral Neuroscience 7, 1-17.

Newman-Norlund, R.D., Ganesh, S., van Schie, H.T., De Bruijn, E.R.A., Bekkering, H., 2009. Self-identification and empathy modulate error-related brain activity during the observation of penalty shots between friend and foe. Social Cognitive and Affective Neuroscience 4, 10-22.

Nichols, T., Brett, M., Andersson, J., Wager, T., Poline, J.-B., 2005. Valid conjunction inference with the minimum statistic. NeuroImage 25, 653-660.

Nieuwenhuis, S., Ridderinkhof, K.R., Blom, J., Band, G.P., Kok, A., 2001. Error-related brain potentials are differentially related to awareness of response errors: evidence from an antisaccade task. Psychophysiology 38, 752-760.

Notebaert, W., Houtman, F., Opstal, F.V., Gevers, W., Fias, W., Verguts, T., 2009. Post-error slowing: an orienting account. Cognition 111, 275-279.

Núñez Castellar, E., Notebaert, W., Van den Bossche, L., Fias, W., 2011. How monitoring other's actions influences one's own performance. Experimental Psychology 58, 499-508.

O'Connell, R.G., Dockree, P.M., Bellgrove, M.A., Kelly, S.P., Hester, R., Garavan, H., Robertson, I.H., Foxe, J.J., 2007. The role of cingulate cortex in the detection of errors with and without awareness: a high-density electrical mapping study. The European Journal of Neuroscience 25, 2571-2579.

Olvet, D.M., Hajcak, G., 2008. The error-related negativity (ERN) and psychopathology: toward an endophenotype. Clinical psychology review 28, 1343-1354.

Overbeek, T.J.M., Nieuwenhuis, S., Ridderinkhof, K.R., 2005a. Dissociable Components of Error Processing. Journal of Psychophysiology 19, 319-329.

Overbeek, T.J.M., Nieuwenhuis, S., Ridderinkhof, K.R., 2005b. Dissociable Components of Error Processing On the Functional Significance of the Pe. 19, 319-329.

Overwalle, F.V., 2009. Social cognition and the brain: A meta-analysis. Human Brain Mapping 30, 829-858.

Papez, J.W., 1937. A proposed mechanism of emotion. Archives of neurology and psychiatry 38, 725-725.

Pessoa, L., 2008. On the relationship between emotion and cognition. Nature Reviews Neuroscience 9, 148-158.

Phelps, E.A., 2006. Emotion and cognition: insights from studies of the human amygdala. Annu. Rev. Psychol. 57, 27-53.

Polli, F.E., Barton, J.J., Thakkar, K.N., Greve, D.N., Goff, D.C., Rauch, S.L., Manoach, D.S., 2008. Reduced error-related activation in two anterior cingulate circuits is related to impaired performance in schizophrenia. Brain 131, 971-986. 
Polli, F.E., Wright, C.I., Milad, M.R., Dickerson, B.C., Vangel, M., Barton, J.J., Rauch, S.L., Manoach, D.S., 2009. Hemispheric differences in amygdala contributions to response monitoring. Neuroreport 20, 398-402.

Pourtois, G., Vocat, R., N'Diaye, K., Spinelli, L., Seeck, M., Vuilleumier, P., 2010. Errors recruit both cognitive and emotional monitoring systems: simultaneous intracranial recordings in the dorsal anterior cingulate gyrus and amygdala combined with fMRI. Neuropsychologia 48, 11441159.

Proudfit, G.H., Inzlicht, M., Mennin, D.S., 2013. Anxiety and error monitoring: the importance of motivation and emotion. Frontiers in human neuroscience 7.

Qiu, J., Yu, C., Li, H., Jou, J., Tu, S., Wang, T., Wei, D., Zhang, Q., 2010. The impact of social comparison on the neural substrates of reward processing: an event-related potential study. NeuroImage 49, 956-962.

Rabbitt, P.M., 1966. Errors and error correction in choice-response tasks. Journal of Experimental Psychology 71, 264-272.

Radke, S., de Lange, F.P., Ullsperger, M., de Bruijn, E.R.A., 2011. Mistakes that affect others: An fMRI study on processing of own errors in a social context. Experimental Brain Research 211, 405-413.

Rak, N., Bellebaum, C., Thoma, P., 2013. Empathy and feedback processing in active and observational learning. Cognitive, Affective, \& Behavioral Neuroscience, 1-16.

Ridderinkhof, K.R., 2004. The Role of the Medial Frontal Cortex in Cognitive Control. Thought A Review Of Culture And Idea 306, 443-447.

Ridderinkhof, K.R., Ramautar, J.R., Wijnen, J.G., 2009. To PE or not to PE: A P3-like ERP component reflecting the processing of response errors. Psychophysiology 46, 531-538.

Ridderinkhof, K.R., Ullsperger, M., Crone, E.A., Nieuwenhuis, S., 2004. The role of the medial frontal cortex in cognitive control. Science 306, 443-447.

Ruby, P., Decety, J., 2001. Effect of subjective perspective taking during simulation of action: a PET investigation of agency. Nature Neuroscience 4, 546-550.

Rushworth, M.F.S., Behrens, T.E.J., Rudebeck, P.H., Walton, M.E., 2007. Contrasting roles for cingulate and orbitofrontal cortex in decisions and social behaviour. Trends in Cognitive Sciences 11, 168-176.

Sagaspe, P., Schwartz, S., Vuilleumier, P., 2011. Fear and stop: a role for the amygdala in motor inhibition by emotional signals. Neuroimage 55, 1825-1835.

Sallet, J., Rushworth, M.F.S., 2009. Should I stay or should I go: genetic bases for uncertaintydriven exploration. Nature neuroscience 12, 963-965.

Sander, D., Grafman, J., Zalla, T., 2003. The human amygdala: an evolved system for relevance detection. Reviews in the Neurosciences 14, 303-316.

Sato, A., Yasuda, A., 2005. Illusion of sense of self-agency: discrepancy between the predicted and actual sensory consequences of actions modulates the sense of self-agency, but not the sense of self-ownership. Cognition 94, 241-255.

Saxe, R., Wexler, A., 2005. Making sense of another mind: the role of the right temporo-parietal junction. Neuropsychologia 43, 1391-1399.

Scherer, K.R., 1984. On the nature and the function of emotions: A component process approach, in: Scherer, K.R., Ekman, P. (Eds.), Approaches to emotion. Erlbaum, Hillsdale, NJ, pp. 293317. 
Scherer, K.R., 1988. Criteria for emotion-antecedent appraisals: A review., in: Hamilton, G.H., Bower, G.H., Frijda, N.H. (Eds.), Cognitive perspectives on emotion and motivation. Kluwer, Dordrecht, pp. 89-126.

Schouppe, N., Braem, S., De Houwer, J., Silvetti, M., Verguts, T., Notebaert, W., in revision. No pain, no gain: the bivalent affective nature of cognitive conflic. Cognition.

Schuch, S., Tipper, S.P., 2007. On observing another person's actions: influences of observed inhibition and errors. Perception \& Psychophysics 69, 828-837.

Sebanz, N., Bekkering, H., Knoblich, G., 2006a. Joint action: bodies and minds moving together. Trends in Cognitive Sciences 10, 70-76.

Sebanz, N., Knoblich, G., Prinz, W., Wascher, E., 2006b. Twin peaks: an ERP study of action planning and control in co-acting individuals. Journal of Cognitive Neuroscience 18, 859-870.

Seeley, W.W., Menon, V., Schatzberg, A.F., Keller, J., Glover, G.H., Kenna, H., Reiss, A.L., Greicius, M.D., 2007. Dissociable Intrinsic Connectivity Networks for Salience Processing and Executive Control. The Journal of Neuroscience 27, 2349-2356.

Seth, A.K., Suzuki, K., Critchley, H.D., 2011. An interoceptive predictive coding model of conscious presence. Front Psychol 2, 395.

Shackman, A.J., Salomons, T.V., Slagter, H.A., Fox, A.S., Winter, J.J., Davidson, R.J., 2011. The integration of negative affect, pain and cognitive control in the cingulate cortex. Nature Reviews Neuroscience 12, 154-167.

Shane, M.S., Stevens, M., Harenski, C.L., Kiehl, K.A., 2008. Neural correlates of the processing of another's mistakes: a possible underpinning for social and observational learning. NeuroImage 42, 450-459.

Shenhav, A., Botvinick, Matthew M., Cohen, Jonathan D., 2013. The Expected Value of Control: An Integrative Theory of Anterior Cingulate Cortex Function. Neuron 79, 217-240.

Sheth, S.a., Mian, M.K., Patel, S.R., Asaad, W.F., Williams, Z.M., Dougherty, D.D., Bush, G., Eskandar, E.N., 2012. Human dorsal anterior cingulate cortex neurons mediate ongoing behavioural adaptation. Nature, 2-6.

Simmonds, D.J., Pekar, J.J., Mostofsky, S.H., 2008. Meta-analysis of Go/No-go tasks demonstrating that fMRI activation associated with response inhibition is task-dependent. Neuropsychologia 46, 224-232.

Simons, R.F., 2010. The way of our errors: Theme and variations. Psychophysiology 47, 1-14.

Singer, T., Critchley, H.D., Preuschoff, K., 2009. A common role of insula in feelings, empathy and uncertainty. Trends in Cognitive Sciences 13, 334-340.

Spunt, R.P., Lieberman, M.D., Cohen, J.R., Eisenberger, N.I., 2012. The phenomenology of error processing: the dorsal ACC response to stop-signal errors tracks reports of negative affect. Journal of Cognitive Neuroscience 24, 1753-1765.

Sridharan, D., Levitin, D.J., Menon, V., 2008. A critical role for the right fronto-insular cortex in switching between central-executive and default-mode networks. Proceedings of the National Academy of Sciences of the United States of America 105, 12569-12574.

Steinhauser, M., Yeung, N., 2010. Decision Processes in Human Performance Monitoring. The Journal of Neuroscience 30, 15643-15653.

Stern, E.R., Liu, Y.N., Gehring, W.J., Lister, J.J., Yin, G., Zhang, J., Fitzgerald, K.D., Himle, J.A., Abelson, J.L., Taylor, S.F., 2010. Chronic medication does not affect hyperactive error responses in obsessive-compulsive disorder. Psychophysiology 47, 913-920. 
Sylvester, C.M., Corbetta, M., Raichle, M.E., Rodebaugh, T.L., Schlaggar, B.L., Sheline, Y.I., Zorumski, C.F., Lenz, E.J., 2012. Functional network dysfunction in anxiety and anxiety disorders. Trends in Neurosciences 35, 527-535.

Takahashi, H., Kato, M., Matsuura, M., Mobbs, D., Suhara, T., Okubo, Y., 2009. When your gain is my pain and your pain is my gain: neural correlates of envy and schadenfreude. Science 323, 937-939.

Taylor, S.F., Stern, E.R., Gehring, W.J., 2007. Neural systems for error monitoring: recent findings and theoretical perspectives. The Neuroscientist 13, 160-172.

Thoma, P., Bellebaum, C., 2012. Your Error's Got me Feeling - How Empathy Relates to the Electrophysiological Correlates of Performance Monitoring. Frontiers in Human Neuroscience 6, 135-135.

Thut, G., Schultz, W., Roelcke, U., Nienhusmeier, M., Missimer, J., Maguire, R.P., Leenders, K.L., 1997. Activation of the human brain by monetary reward. Neuroreport 8, 1225-1228.

Tow, P.M., Whitty, C.W.M., 1953. Personality changes after operations on the cingulate gyrus in man. Journal of Neurology, Neurosurgery \& Psychiatry 16, 186-193.

Ullsperger, M., Harsay, H.A., Wessel, J.R., Ridderinkhof, K.R., 2010. Conscious perception of errors and its relation to the anterior insula. Brain Structure \& Function 214, 629-643.

Ullsperger, M., von Cramon, D.Y., 2001. Subprocesses of performance monitoring: a dissociation of error processing and response competition revealed by event-related fMRI and ERPs. NeuroImage 14, 1387-1401.

Vaidyanathan, U., Nelson, L.D., Patrick, C.J., 2012. Clarifying domains of internalizing psychopathology using neurophysiology. Psychol Med 42, 447-459.

Van Meel, C.S., Van Heijningen, C.A.A., 2010. The effect of interpersonal competition on monitoring internal and external error feedback. Psychophysiology 47, 213-222.

van Schie, H.T., Mars, R.B., Coles, M.G.H., Bekkering, H., 2004. Modulation of activity in medial frontal and motor cortices during error observation. Nature Neuroscience 7, 549-554.

Van Veen, V., Carter, C.S., 2002. The timing of action-monitoring processes in the anterior cingulate cortex. Journal of Cognitive Neuroscience 14, 593-602.

Vesper, C., Butterfill, S., Knoblich, G., Sebanz, N., 2010. A minimal architecture for joint action. Neural Networks 23, 998-1003.

Vocat, R., Pourtois, G., Vuilleumier, P., 2008. Unavoidable errors: a spatio-temporal analysis of time-course and neural sources of evoked potentials associated with error processing in a speeded task. Neuropsychologia 46, 2545-2555.

Vuilleumier, P., 2005. How brains beware: neural mechanisms of emotional attention. Trends in Cognitive Sciences 9, 585-594.

Wagner, D.D., Haxby, J.V., Heatherton, T.F., 2012a. The Representation of Self and Person Knowledge in the Medial Prefrontal Cortex. Wiley Interdiscip Rev Cogn Sci 3, 451-470.

Wagner, U., Handke, L., Dörfel, D., Walter, H., 2012b. An Experimental Decision-Making Paradigm to Distinguish Guilt and Regret and Their Self-Regulating Function via Loss Averse Choice Behavior. Frontiers in psychology 3, 431-431.

Wagner, U., N'Diaye, K., Ethofer, T., Vuilleumier, P., 2011. Guilt-specific processing in the prefrontal cortex. Cerebral Cortex 21, 2461-2470.

Walsh, M.M., Anderson, J.R., 2012. Learning from experience: Event-related potential correlates of reward processing, neural adaptation, and behavioral choice. Neuroscience \& Biobehavioral Reviews 36, 1870-1884. 
Weinberg, A., Olvet, D.M., Hajcak, G., 2010. Increased error-related brain activity in generalized anxiety disorder. Biological Psychology 85, 472-480.

Weissman, D.H., Roberts, K.C., Visscher, K.M., Woldorff, M.G., 2006. The neural bases of momentary lapses in attention. Nature Neuroscience 9, 971-978.

Wessel, J.R., 2012. Error awareness and the error-related negativity: evaluating the first decade of evidence. Front Hum Neurosci 6, 88.

Wessel, J.R., Danielmeier, C., Morton, J.B., Ullsperger, M., 2012. Surprise and error: common neuronal architecture for the processing of errors and novelty. The Journal of Neuroscience 32, 7528-7537.

Wessel, J.R., Danielmeier, C., Ullsperger, M., 2011. Error awareness revisited: accumulation of multimodal evidence from central and autonomic nervous systems. Journal of Cognitive Neuroscience 23, 3021-3036.

Whalen, P.J., Shin, L.M., McInerney, S.C., Fischer, H., Wright, C.I., Rauch, S.L., 2001. A functional MRI study of human amygdala responses to facial expressions of fear versus anger. Emotion (Washington, D.C.) 1, 70-83.

Yarkoni, T., Poldrack, R.A., Nichols, T.E., Van Essen, D.C., Wager, T.D., 2011a. Large-scale automated synthesis of human functional neuroimaging data. Nature Methods 8, 665-670.

Yarkoni, T., Poldrack, R.A., Van Essen, D.C., Wager, T.D., 2011b. Cognitive neuroscience 2.0: building a cumulative science of human brain function. Trends in Cognitive Sciences 14, 489496.

Yeung, N., Botvinick, M.M., Cohen, J.D., 2004. The neural basis of error detection: conflict monitoring and the error-related negativity. Psychological Review 111, 931-959.

Yoshida, K., Saito, N., Iriki, A., Isoda, M., 2012. Social error monitoring in macaque frontal cortex. Nature neuroscience.

Yu, H., Hu, J., Hu, L., Zhou, X., 2013. The voice of conscience: Neural bases of interpersonal guilt and compensation. Social cognitive and affective neuroscience.

Yu, R., Zhou, X., 2006. Brain responses to outcomes of one's own and other's performance in a gambling task. Neuroreport 17, 1747-1751. 


\section{Figure captions}

\section{Figure 1 - Event-related components generated at different stages of action}

monitoring for self-generated and observed actions. Conflict (e.g. interference with irrelevant stimulus dimensions or incongruent stimulus-response mapping) leads to the conflict-N2 peaking 300 ms following stimulus presentation. At the response level, errors are accompanied by a rapid negative deflection over fronto-central electrodes, the error-related negativity (ERN), that is paralleled by a much smaller correct-related negativity $(\mathrm{CRN})$ for correct responses. Following the ERN, a large fronto-central positivity (the error positivity, Pe) can be measured around 100$300 \mathrm{~ms}$ following response onset. The ERN is generally thought to reflect a generic error or conflict detection mechanism, with sources typically located in the dACC (Debener et al., 2005; Dehaene et al., 1994; Doñamayor et al., 2011; Herrmann et al., 2004; Van Veen and Carter, 2002). The functional characteristics of the Pe are still debated, but this positive deflection may relate to error awareness (Dhar et al., 2011; Endrass et al., 2005; Endrass et al., 2007; Klein et al., 2007; Nieuwenhuis et al., 2001; O'Connell et al., 2007; Steinhauser and Yeung, 2010; Ullsperger et al., 2010; Wessel et al., 2011), motivational aspects such as error salience (Ridderinkhof et al., 2009), and post-error adjustments in behavioral control (Falkenstein et al., 2000; Nieuwenhuis et al., 2001; Overbeek et al., 2005a; Ridderinkhof et al., 2009; Vocat et al., 2008). The Pe appears to be generated in either more rostral or rather posterior cingulate cortex regions (Herrmann et al., 2004; Van Veen and Carter, 2002; Vocat et al., 2008), alongside additional sources in insula and orbitofrontal cortex (Dhar et al., 2011). Similar response-locked components are evoked when observing another person's errors (observer ERN and observer Pe), albeit with longer latencies (Carp et al., 2009; Koban et al., 2010; Miltner et al., 2004; van Schie et al., 2004). When external visual feedback is necessary to evaluate the outcome of an 
action, the feedback-related negativity (FRN) can be measured around $250 \mathrm{~ms}$ following feedback presentation, The FRN has similar generators as the ERN in dACC/dMFC or, alternatively, in more anterior medial prefrontal cortex (Gehring and Willoughby, 2002; Gentsch et al., 2009; Miltner et al., 1997). The FRN is sometimes followed by a positive deflection, the feedback P300. Observing another person's feedback leads to an observer FRN component (oFRN) that strongly resembles the FRN in latency and topography (Koban et al., 2012b; Yu and Zhou, 2006).

Figure 2 - Neurosynth term-based meta-analytic activation maps. A) Significant activation for the terms 'Error' (red) and 'Emotion' (blue) with a significance threshold of $p<$ 0.05 (FDR corrected for multiple comparisons). Their conjunction (yellow) reveals common activation in anterior insula (AI), dorsal mediofrontal cortex (dMFC) and lateral prefrontal areas (LPFC), as well as basal ganglia. B) Significant activation ( $p<0.05$ FDR corrected) for 'Error' (red) and 'Social' (green), and their conjunction in AI, dMFC, and LPFC (yellow). Accordingly, these brain regions appear to be important for a dynamic integration of action monitoring processes with affective and social factors.

Figure 3 - A framework for social and affective influences on action monitoring. Both $\mathrm{dMFC} / \mathrm{dACC}$ and AI contribute to the monitoring of actions and to triggering adjustments in cognitive control that is implemented by lateral prefrontal areas and more generally the frontoparietal attention network. Yet, they have slightly different and complementary roles. DMFC/dACC might be responsible for the fast (e.g. pre-conscious) detection of errors, conflicts, and reward prediction errors (resulting in the ERN component), thereby monitoring actions along 
a valence dimension using simple heuristics. This information could be used to thereby trigger automatic adjustments in cognitive control (Botvinick et al., 2001; Ridderinkhof, 2004; Shenhav et al., 2013). Functional connectivity with the amygdala and other limbic structures during error monitoring (Pourtois et al., 2010) may mediate autonomic responses to errors, and be associated with negative affective-motivational states that are automatically elicited by aversive action outcomes (Aarts et al., 2012). On the other hand, AI could be crucial for conscious aspects of error monitoring (Ullsperger et al., 2010), for integrating action outcomes with self-agency (Brass and Haggard, 2010; Farrer and Frith, 2002), and social context information (Koban et al., 2013a), which may lead to the experience of more complex and situation-specific emotional feeling states (Brass and Haggard, 2010; Craig, 2009; Critchley et al., 2004; Koban et al., 2013a). These situation-specific feeling states (e.g. the experience of guilt when errors have negative consequences for others, regret when having chosen the wrong option, or anger when another person makes an important mistake) may underlie a more deliberate and flexible mode of behavioral adjustments and cognitive control. 


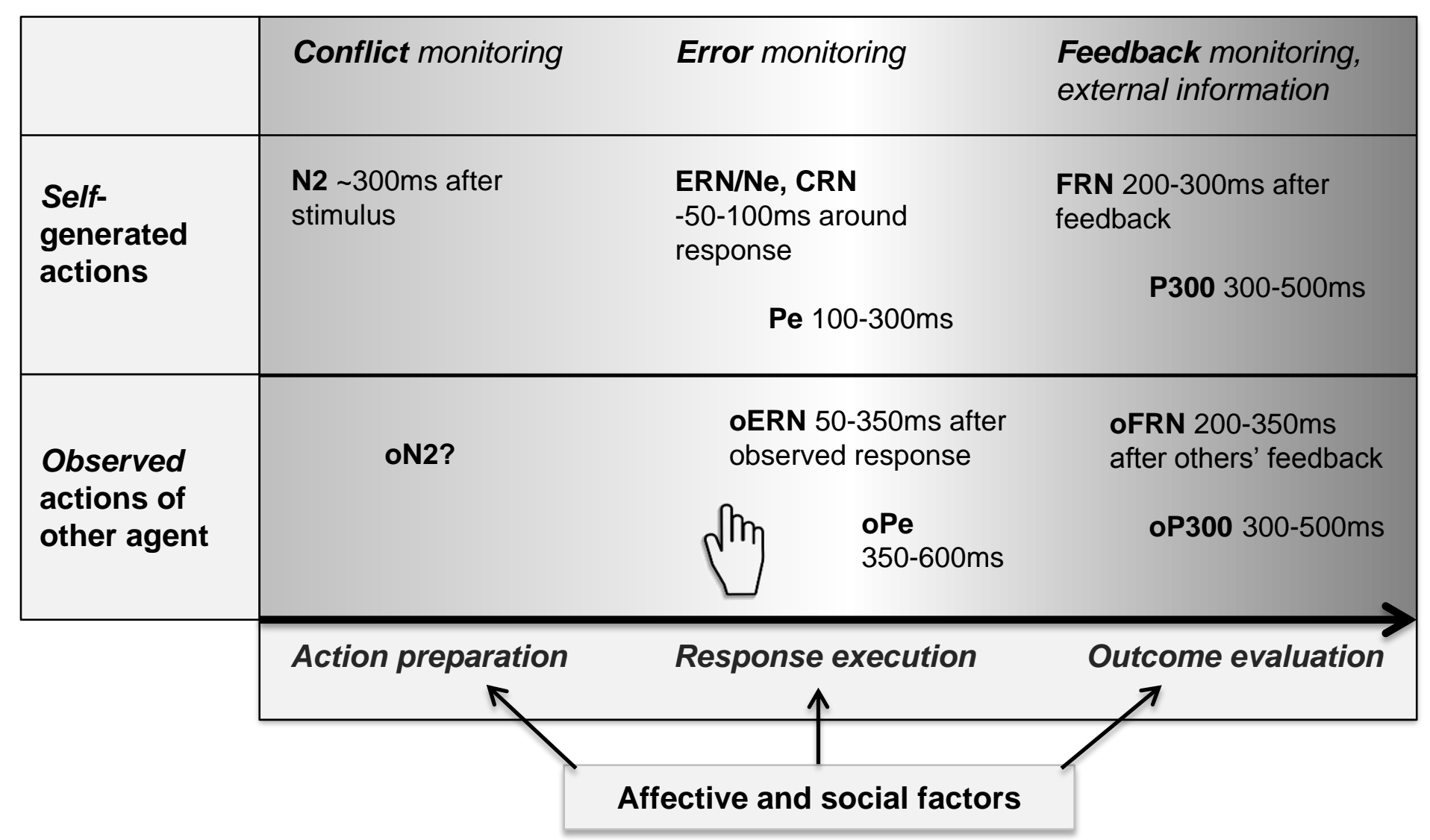

Figure 1 
A 'Emotion' AND ‘Errors', $p<0.05$ FDR correct
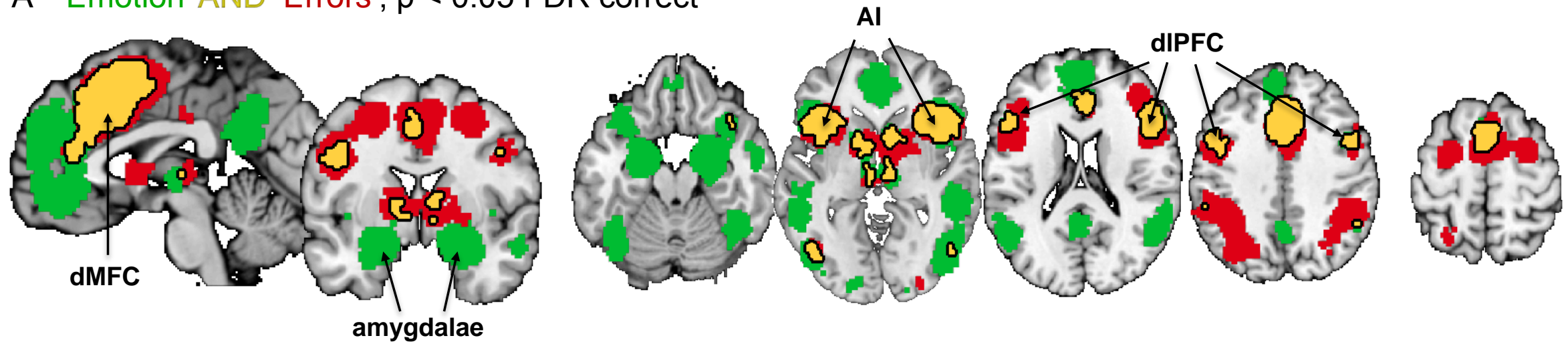

B 'Social' AND 'Errors', $p<0.05$ FDR correct
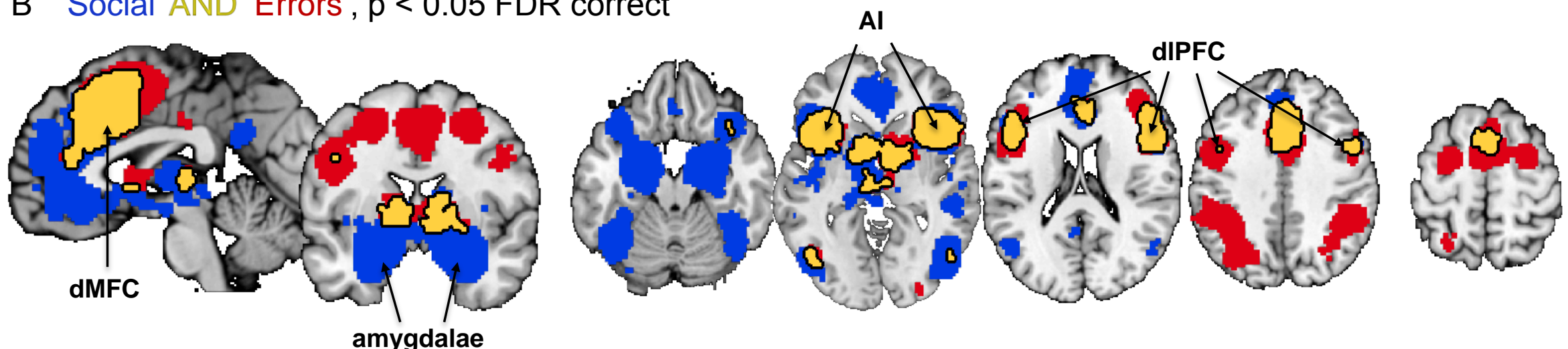

Figure 2 


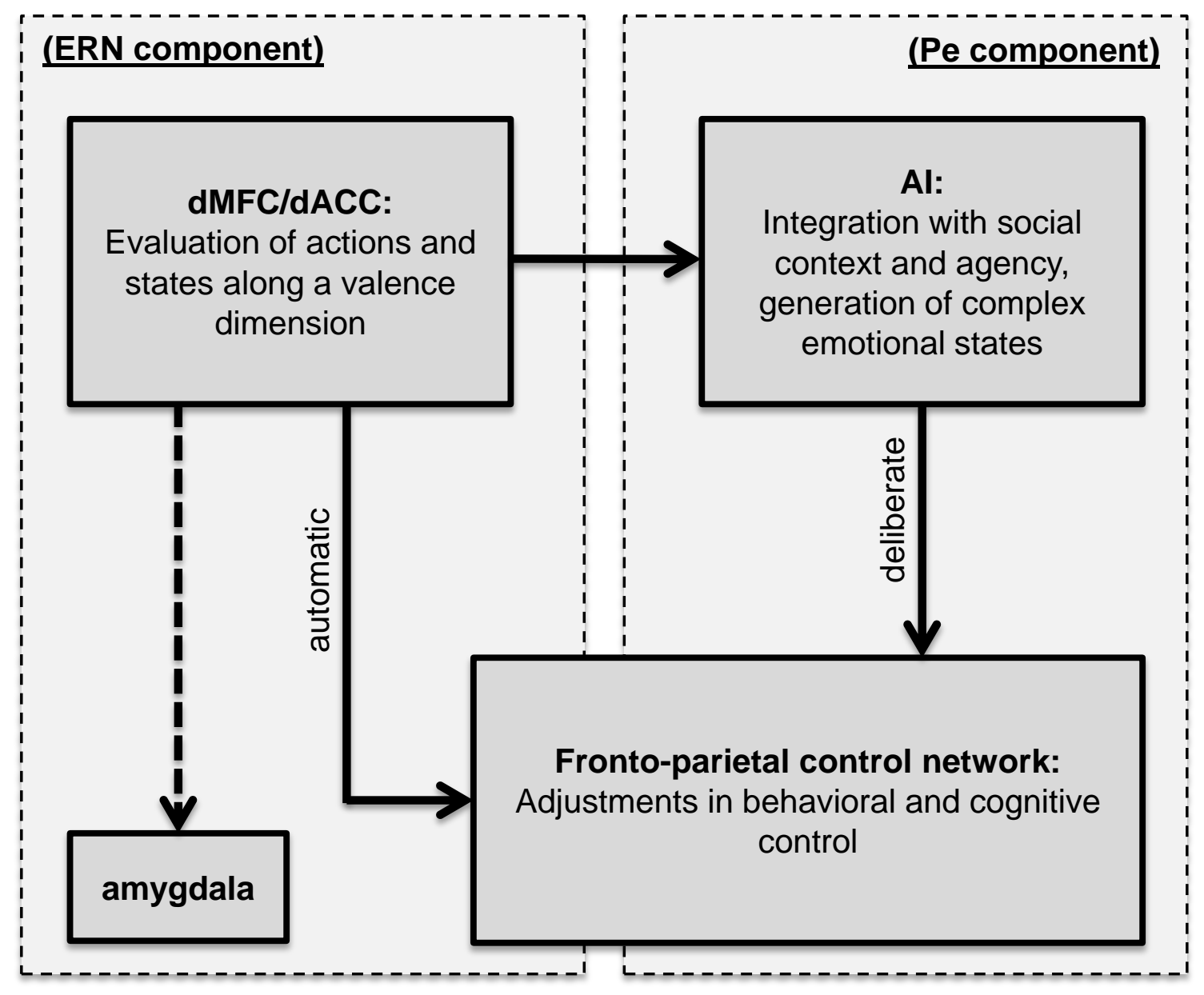

Figure 3 